Article

\title{
Comparison of Coniferous Plantation Heights Using Unmanned Aerial Vehicle (UAV) Laser Scanning and Stereo Photogrammetry
}

\author{
Mei Li ${ }^{1,2}$, Zengyuan Li ${ }^{1,2}$, Qingwang Liu ${ }^{1,2, * \mathbb{C}}$ and Erxue Chen ${ }^{1,2}$ \\ 1 Institute of Forest Resource Information Techniques, Chinese Academy of Forestry, Beijing 100091, China; \\ limei@ifrit.ac.cn (M.L.); zy@caf.ac.cn (Z.L.); chenerx@ifrit.ac.cn (E.C.) \\ 2 Key Laboratory of Forestry Remote Sensing and Information System, National Forestry and Grassland \\ Administration, Beijing 100091, China \\ * Correspondence: liuqw@ifrit.ac.cn; Tel.: +86-010-6288-9804
}

check for updates

Citation: Li, M.; Li, Z.; Liu, Q.; Chen, E. Comparison of Coniferous

Plantation Heights Using Unmanned Aerial Vehicle (UAV) Laser Scanning and Stereo Photogrammetry. Remote Sens. 2021, 13, 2885. https://doi.org/ $10.3390 /$ rs13152885

Academic Editor: Luke Wallace

Received: 21 May 2021

Accepted: 20 July 2021

Published: 23 July 2021

Publisher's Note: MDPI stays neutral with regard to jurisdictional claims in published maps and institutional affiliations.

Copyright: (c) 2021 by the authors. Licensee MDPI, Basel, Switzerland. This article is an open access article distributed under the terms and conditions of the Creative Commons Attribution (CC BY) license (https:// creativecommons.org/licenses/by/ $4.0 /)$.

\begin{abstract}
Plantation forests play a critical role in forest products and ecosystems. Unmanned aerial vehicle (UAV) remote sensing has become a promising technology in forest related applications. The stand heights will reflect the growth and competition of individual trees in plantation. UAV laser scanning (ULS) and UAV stereo photogrammetry (USP) can both be used to estimate stand heights using different algorithms. Thus, this study aimed to deeply explore the variations of four kinds of stand heights including mean height, Lorey's height, dominated height, and median height of coniferous plantations using different models based on ULS and USP data. In addition, the impacts of thinned point density of 30 pts to $10 \mathrm{pts}, 5 \mathrm{pts}, 1 \mathrm{pts}$, and $0.8 \mathrm{pts} / \mathrm{m}^{2}$ were also analyzed. Forest stand heights were estimated from ULS and USP data metrics by linear regression and the prediction accuracy was assessed by 10 -fold cross validation. The results showed that the prediction accuracy of the stand heights using metrics from USP was basically as good as that of ULS. Lorey's height had the highest prediction accuracy, followed by dominated height, mean height, and median height. The correlation between height percentiles metrics from ULS and USP increased with the increased height. Different stand heights had their corresponding best height percentiles as variables based on stand height characteristics. Furthermore, canopy height model (CHM)-based metrics performed slightly better than normalized point cloud (NPC)-based metrics. The USP was not able to extract exact terrain information in a continuous coniferous plantation for forest canopy cover (CC) over 0.49. The combination of USP and terrain from ULS can be used to estimate forest stand heights with high accuracy. In addition, the estimation accuracy of each forest stand height was slightly affected by point density, which can also be ignored.
\end{abstract}

Keywords: forest stand height; UAV laser scanning; UAV stereo photogrammetry; point clouds density; CHM; metrics

\section{Introduction}

Plantation forests, accounting for 7.3\% (290 million ha) of the world's forest cover (3999 million ha) [1], play a critical role in the restoration and reconstruction of forest ecosystems, the provision of forest products, the increase in forest carbon sink, the improvement of ecological environment, meeting demands for wood and other forest products [2,3]. The covering area of planted forests in China is the largest worldwide and is about approximately $36 \%$ of the total national forest coverage [4]. As is widely-known, regardless of the purpose of plantation forest management, ecological benefits, or economic benefits, plantation forests are inseparable from forest management decision-making. Forest structural attributes and biophysical properties reflect the growth and health of the forests to a certain extent. Therefore, efficient and accurate estimations of the properties of plantation 
forests are critically important for forest managers to quantitatively understand the forests' condition [5].

Forest height is an important parameter required for forest management, inventory, and monitoring [6]. Additionally, it is also an ecological measure that provides essential information related to ecological, hydrological, biophysical, and micro-meteorological properties [7]. As such, the estimation accuracy and variations of forest height is sensitive to the estimation accuracy of above ground biomass (AGB) [8], which plays a critical role in programs aimed at reducing the global emissions of carbon from deforestation and the degradation of forests [9]. Forest canopy height is defined as the height of the upper envelope of tree crown above terrain, while forest stand height is defined as the statistic height of tree height in a forest stand [10].

Light Detection and Ranging (LiDAR) has the ability to penetrate forest canopy to acquire 3-dimentional information of the observation target based on the time difference between the emission and return of the laser pulses [11]. In recent years, with the development of photogrammetry algorithms, computer technology and stereo photogrammetry images also have the ability to generate dense point clouds with 3-dimentional characteristics. Subsequently, the exploitation of unmanned aerial vehicle (UAV) systems promotes the flexibility of forest attribute estimation at small-scale [12] or large-scale forest inventory [13], which mainly include the two technologies, UAV laser scanning (ULS) and UAV stereo photogrammetry (USP). The common characteristic of the two technologies is its corresponding capability of generating 3D point clouds data, which have great suitability for forest attribute estimation $[14,15]$. Some comparisons considering the capacity of USP and ALS on forests have been done to analyze the suitability of USP to be an alternative of ULS [16,17]. A variety of comparable studies on the performance of LiDAR and USP point clouds for forest attribute parameters have been conducted [16] including diverse forest environments such as complex boreal forest types, complex coastal forest [18], and subtropical planted forests [19]. Most studies have concluded that LiDAR provides higher accuracy for modeling and predicting forest attributes than stereo photogrammetry data [20-22]. However, few studies have analyzed the performance of USP on temperate coniferous plantations in mountainous area.

In contrast to LiDAR, dense point clouds generated from photogrammetry images are limited to the canopy envelope of tree crown above terrain. The vertical distributions of NPC or CHM from ULS and USP were more similar with the increasing heights [23]. Metrics mainly including height metrics and density metrics representing the vertical distribution of canopy having strong correlation with forest structural attributes [24,25], especially with forest height. In operational forest inventories, an area-based approach (ABA) is more widely used to estimate forest stand heights and other forest attributes using metrics calculated from point clouds or CHM by linear regression [12], non-linear regressions [16,20], and machine learning methods [26,27]. Noordermeer et al. [20] estimated Lorey's height and dominated height in five districts dominated by coniferous forests in southeastern Norway using height metrics and density metrics from ALS point clouds and aerial photogrammetry by nonlinear prediction models. Mean height and median height were successfully estimated by UAV photogrammetry using simple linear regression with high accuracy [28]. Järnstedt et al. [27] compared the estimation accuracy of mean and dominant height using aerial imagery and ALS data. Puliti et al. [12] compared the performance of USP and ULS data to estimate Lorey's height and dominated height. Tompalski et al. [29] assessed the capability of ALS and aerial photogrammetry data to estimate Lorey's height. What we can observe from previous publications is that the commonly used observed forest stand heights are mean height, Lorey's height, dominated height, and median height, but they have been rarely systematically and comprehensively analyzed in one study using the metrics from ULS or USP, respectively. More study needs to be conducted to deeply understand the questions related with forest heights estimated using ULS and USP. For example, are the estimation accuracies of forest heights using a low-cost consumer-grade camera similar to those using ULS in temperate coniferous 
plantations taking into account the studied forest type in the current literature? What kind of forest height such as Lorey's height, dominated height, arithmetic mean height, and median height has a better performance using ULS and USP? Additionally, the difference of flight parameters between LiDAR and stereo photogrammetry flight task and the point cloud density of ULS and USP point clouds may be different. While point density is one of important factors affecting the estimating accuracy of forest structure attributes [30-33], it may be more persuasive for comparisons between ULS and USP point clouds with similar point cloud density. However, previous publications on the comparison between the ULS and USP have rarely considered the effect of point cloud density difference on the performance of the ULS and USP on forest structural estimation.

In this paper, we selected a typical coniferous plantation in a mountainous area of northern China to testify the potential of ULS and USP point clouds to estimate different forest heights. The objectives of this study were to (1) compare the capability of ULS and USP data to estimate forest stand heights; (2) identify the optimal forest stand height model among the four commonly used forest stand heights; and (3) evaluate the effects of point density on the estimation of forest heights. These will be very useful for forest inventory and management.

\section{Materials and Methods}

\subsection{Study Site}

The study site is located at the Wangyedian forest farm $\left(118^{\circ} 9^{\prime} \sim 118^{\circ} 30^{\prime} \mathrm{E}, 41^{\circ} 21^{\prime} \sim 41^{\circ} 39^{\prime} \mathrm{N}\right)$ in Inner Mongolia Autonomous Province, China, and covers approximately $5.52 \times 104 \mathrm{hm}^{2}$ (Figure 1). The elevation ranges from $800 \mathrm{~m}$ to $1890 \mathrm{~m}$ above sea level and it belongs to a semi-arid warm temperate continental climate. The annual temperature changes from $-31^{\circ}$ to $36{ }^{\circ} \mathrm{C}$ with an annual average temperature of $4.2^{\circ} \mathrm{C}$. The annual precipitation is about 400 600 mm, which mainly occurs in July and August. The dominate tree species of the plantation are L. principis-rupprechtii (Larix principis-rupprechtii) and P. tabuliformis (Pinus tabuliformis) while other areas are covered by Betula platyphylla and Betula dahurica Pallas. The plantation stage ranges from young to near-mature forest.

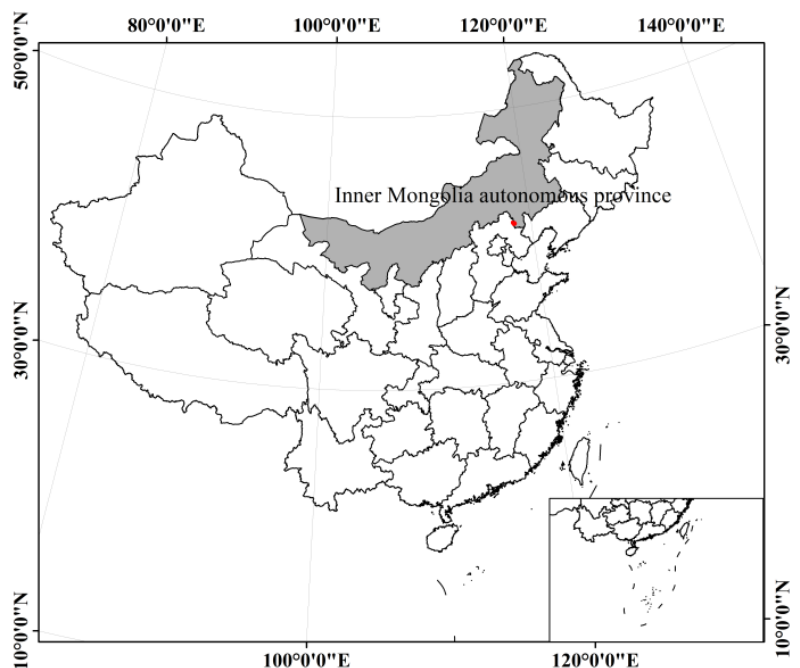

(a)

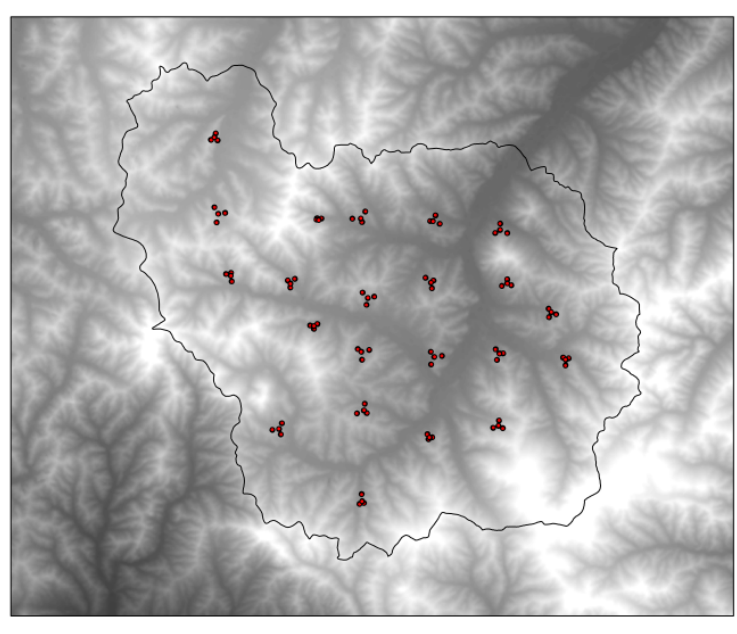

(b)

Figure 1. Overview of study area. (a) Location of the study site in the Wangyedian forest farm in Inner Mongolia Autonomous Province, China; and (b) Spatial distribution of plots (red dots indicate plot centers overlaid on ASTER GDEM of $30 \mathrm{~m}$ resolution, the grey line is the boundary of Wangyedian forest farm). 


\subsection{Field Data}

There are 19 blocks regularly distributed in the study area, and four plots of $25 \mathrm{~m} \times 25 \mathrm{~m}$ were designed in each block (Figure 1b). The diameter at breast heights (DBHs), species, tree heights $(\mathrm{m})$, and crown widths $(\mathrm{m})$ at perpendicular directions of north-south and east-west of individual trees with DBH $\geq 5 \mathrm{~cm}$ were measured in September 2019. The number of plots dominated with L. principis-rupprechtii (denoted as LYS) and P. tabuliformis (denoted as YS) were 30 and 41, respectively, and used as references to assess the accuracy of the estimated stand heights.

The heights of individual trees of all plots varied from $2 \mathrm{~m}$ to $24.1 \mathrm{~m}$ with a mean of $11.23 \mathrm{~m}$. The mean of tree heights of the LYS and YS plots were $11.67 \mathrm{~m}$ and $11.05 \mathrm{~m}$, respectively. The histogram of tree heights of the LYS and YS plots has a unmoral and bimodal distribution, respectively, as shown in Figure 2. The stand densities varied from 435 to 4097 stems $/ \mathrm{hm}^{2}$. The descriptive statistics of plots are summarized in Table 1 .

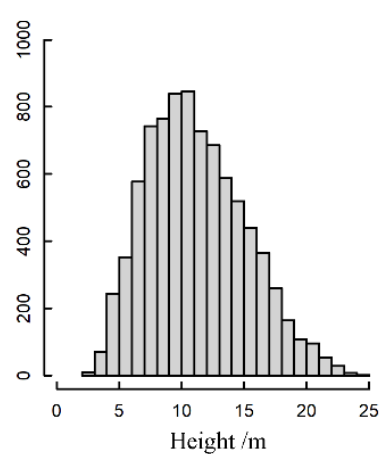

(a)

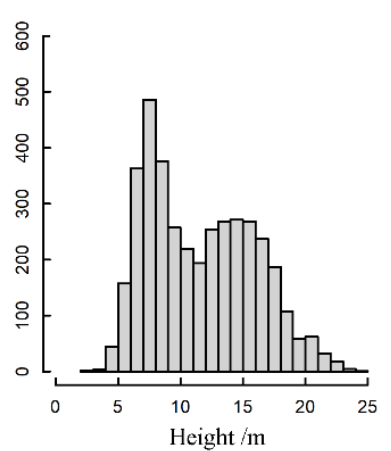

(b)

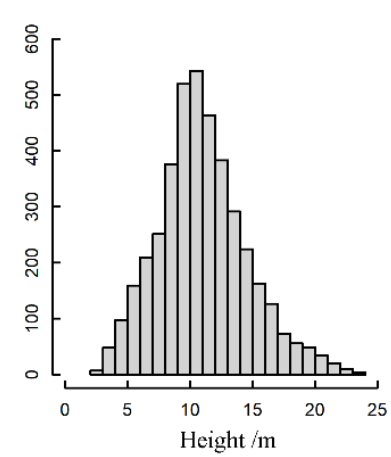

(c)

Figure 2. Histogram of tree heights of different forest cases (ALL plots (a), LYS plots (b), YS plots (c)).

The Lorey's height $\left(H_{L}\right)$, mean height $\left(H_{A}\right)$, dominated height $\left(H_{D o m}\right)$, and median height $\left(H_{M e d}\right)$ were calculated as forest stand height. $H_{L}$, calculated using DBH and height, the two critical parameters of each tree, could better represent the stand height. $H_{A}$ is the average height of all individual trees with $\mathrm{DBH} \geq 5 \mathrm{~cm}$ in each ground plot. $H_{\text {Dom }}$ is the average height of $20 \%$ top trees [34]. $H_{M e d}$ is the median height of each plot.

$$
\begin{gathered}
H_{L}=\frac{\sum_{i=1}^{n} h_{i} G_{i}}{\sum_{i=1}^{n} G_{i}} \\
G_{i}=\frac{\pi D_{i}^{2}}{4} \\
H_{A}=\frac{\sum_{i=1}^{n} h_{i}}{n}
\end{gathered}
$$

where $h_{i}$ is the height of $i^{\text {th }}$ individual tree; $n$ is the number of sample plots; $G_{i}$ is basal area at $1.3 \mathrm{~m}$ height of $i^{\text {th }}$ individual tree; and $D_{i}$ is diameter of $i^{\text {th }}$ individual tree.

The boxplots of the four forest stand heights within different forest cases are shown in Figure 3, which indicated that the interquartile range of ALL plots (Figure 3a) and LYS plots (Figure $3 b$ ) were similar, while the medians of the four forest heights from LYS plots were significantly greater than that of ALL plots. For YS plots (Figure 3c), the interquartile range of the three stand heights including Lorey's height, mean height, and median height were shorter than those of the LYS and ALL plots. 
Table 1. Descriptive statistics of field plots.

\begin{tabular}{|c|c|c|c|c|c|}
\hline Forest Parameters & Symbol & Range & Median & Mean & SD \\
\hline \multicolumn{6}{|c|}{ ALL plots $(n=71)$} \\
\hline Stand density/(stems ha $\left.{ }^{-1}\right)$ & $N$ & $435-4097$ & 1714 & 1728 & 695 \\
\hline Mean DBH/cm & $D B H$ & $7.70-31.20$ & 14.00 & 15.18 & 4.73 \\
\hline Canopy cover & $\mathrm{CC}$ & $0.42-0.87$ & 0.63 & 0.63 & 0.09 \\
\hline Lorey's height/m & $H_{L}$ & $6.80-20.80$ & 12.80 & 13.39 & 3.49 \\
\hline Mean height/m & $H_{A}$ & $6.60-20.50$ & 12.20 & 12.39 & 3.49 \\
\hline Dominated height/m & $H_{\text {Dom }}$ & $8.00-22.70$ & 15.30 & 15.24 & 3.69 \\
\hline Median height/m & $H_{M e d}$ & $6.6-20.70$ & 12.40 & 12.66 & 3.69 \\
\hline Volume $/\left(\mathrm{m}^{3} \mathrm{ha}^{-2}\right)$ & $V$ & $62.40-374.40$ & 206.40 & 209.67 & 70.70 \\
\hline \multicolumn{6}{|c|}{ LYS plots $(n=30)$} \\
\hline Stand density /(stems ha $\left.{ }^{-1}\right)$ & $N$ & 528-4097 & 1794 & 1902 & 768 \\
\hline Mean DBH/cm & $D B H$ & $7.70-22.50$ & 14.15 & 14.02 & 3.89 \\
\hline Canopy cover & $C C$ & $0.43-0.87$ & 0.66 & 0.65 & 0.10 \\
\hline Lorey's height/m & $H_{L}$ & $6.80-20.80$ & 14.80 & 13.76 & 3.85 \\
\hline Mean height/m & $H_{A}$ & $6.60-20.50$ & 13.85 & 13.00 & 3.77 \\
\hline Dominated height/m & $H_{\text {Dom }}$ & $8.00-22.70$ & 16.55 & 15.45 & 4.06 \\
\hline Median height/m & $H_{\text {Med }}$ & $6.60-22.70$ & 14.30 & 13.29 & 3.96 \\
\hline Volume $/\left(\mathrm{m}^{3} \mathrm{ha}^{-2}\right)$ & $V$ & $62.40-374.40$ & 220.00 & 208.27 & 83.45 \\
\hline \multicolumn{6}{|c|}{ YS plots $(n=41)$} \\
\hline Stand density/(stems ha $\left.{ }^{-1}\right)$ & $N$ & $435-2536$ & 1674 & 1600 & 615 \\
\hline Mean DBH/cm & $D B H$ & $10.80-31.20$ & 13.80 & 16.03 & 5.14 \\
\hline Canopy cover & $C C$ & $0.42-0.78$ & 0.62 & 0.62 & 0.08 \\
\hline Lorey's height/m & $H_{L}$ & $8.70-20.30$ & 12.30 & 13.12 & 3.22 \\
\hline Mean height/m & $H_{A}$ & $7.80-19.60$ & 11.10 & 11.94 & 3.24 \\
\hline Dominated height/m & $H_{\text {Dom }}$ & $10.10-22.00$ & 14.40 & 15.09 & 3.44 \\
\hline Median height/m & $H_{M e d}$ & 7.30-20.30 & 11.20 & 12.19 & 3.45 \\
\hline Volume $/\left(\mathrm{m}^{3} \mathrm{ha}^{-2}\right)$ & $V$ & $108.80-372.80$ & 206.4 & 210.69 & 60.80 \\
\hline
\end{tabular}

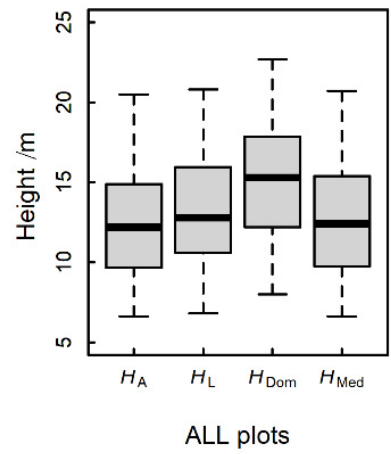

(a)

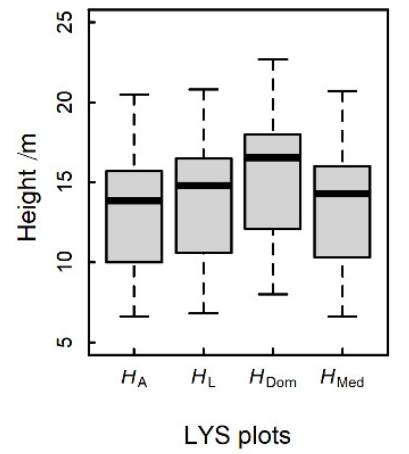

(b)

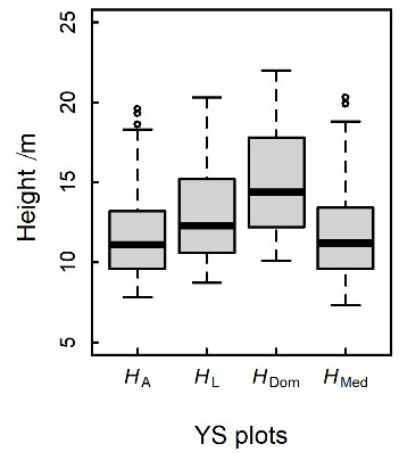

(c)

Figure 3. The boxplots of the four forest stand heights within different forest cases (ALL plots (a), LYS plots (b), YS plots (c)).

\subsection{ULS and USP Datasets}

The ULS datasets were acquired in September and October 2019 over the 19 blocks. A Riegl VUX-1 laser scanner mounted on a RC6-2000 UAV aircraft with eight-rotors was used to acquire LiDAR data at an altitude ranging from $933 \mathrm{~m}$ to $1322 \mathrm{~m}$ above ground level. The flying height was determined by considering the variation of terrain and safety of flight. The differences in height between the lowest and highest points of 19 blocks varied from approximately $162 \mathrm{~m}$ to $263 \mathrm{~m}$ with a mean of $203 \mathrm{~m}$. The actual flying heights above terrain varied from $58 \mathrm{~m}$ to $340 \mathrm{~m}$ with a mean of $202 \mathrm{~m}$. The original point clouds were georeferenced using the high-precision position and orientation (POS) data, and then projected to the coordinate system of Universal Transverse Mercator Zone 50N/WGS-84. The LiDAR point clouds covered about $5.48 \times 102 \mathrm{hm}^{2}$. The average point density varied 
from 107 to $152 \mathrm{pts} / \mathrm{m}^{2}$ in the 19 blocks. The vertical accuracy of LiDAR ranged from $-0.36 \mathrm{~m}$ to $0.19 \mathrm{~m}$.

The USP data were acquired in September 2019 over the 19 blocks on a sunny day using a DJI Phantom 4 RTK, a light-weight and low-cost aircraft carrying a consumer-grade camera. The designed flying heights were approximately $190 \mathrm{~m}$ above the ground level. The images were obtained with along- and across-track overlap of $80 \%$ and $70 \%$ in the 19 blocks, which had a ground sampling resolution of $0.1 \mathrm{~m}$. A total of 14,000 images were acquired during 48 flights across the 19 blocks. The detailed specifications of the UAV laser scanning and photogrammetry system are listed in Table 2.

Table 2. The ULS and USP system specifications.

\begin{tabular}{cccc}
\hline & \multicolumn{2}{c}{ LiDAR } \\
\hline UAV model & RC6-2000 & Rotor & 8 \\
LiDAR model & Riegl VUX-1 & PRF & $10 \mathrm{~Hz} 200 \mathrm{~Hz}$ \\
Laser wavelength & $905 \mathrm{~nm}$ & Laser divergence & $3 \mathrm{mrad}$ \\
Scan pattern & Rotate Mirror & Scan FOV & $30^{\circ} \times 360^{\circ}$ \\
Echoes & 2 & Max Scan frequency & $20 \mathrm{~Hz}$ \\
Range & $3 \mathrm{~m} \sim-920 \mathrm{~m}$ & Vertical Accuracy & $<5 \mathrm{~cm}$ \\
\hline \multicolumn{4}{c}{ Photogrammetry } \\
UAV model & DJI Phantom 4 RTK & Rotor & 3 \\
Camera model & $1 \mathrm{~mm} \mathrm{CMOS}$ & Pixels & $50,320,896$ \\
CMOS size & $36.0 \mathrm{~mm} \times 24.0 \mathrm{~mm}$ & Image size & $4864 \times 3648 \mathrm{pixels}$ \\
FOV & Horizonal 70 & Focal length & $9 \mathrm{~mm}$ \\
Pixel unit & Vertical $\pm 10^{\circ}$ & Bands & $\mathrm{R} / \mathrm{G} / \mathrm{B}$ \\
\hline
\end{tabular}

\subsection{Data Pre-Processing}

\subsubsection{Dense Point Clouds Generation from Images}

The dense three-dimensional point clouds for the 19 blocks were generated with high overlapped images using Agisoft Metashape professional (Version 1.6.2 build 10247). The processing mainly includes images checking, feature identification, matching, and bundle adjustment [35]. The specific data processing instructions of this study can be found in [36]. The point densities of 19 blocks varied from 40 to $75 \mathrm{pts} / \mathrm{m}^{2}$ at $1.0 \mathrm{~m}$ resolution.

\subsubsection{Point Cloud Normalization and CHM Generation}

To make the comparison more accurate and convincing, the registration of LiDAR point clouds and photogrammetry point clouds was primarily conducted by visual and manual editing based on the artificial objects such as buildings and roads [37]. The point clouds were classified into four classes including noise points, ground points, building points, and vegetation points using the Terrasolid software. Noise points were isolated points with obviously higher or lower height value compared with other points, and could be identified using the isolation algorithm or visual evaluation. The isolation algorithm was identified based on the straight distance between two points. As for one point A, if there is only point $A$ in the spherical space with a radius of $5 \mathrm{~m}$ and point $\mathrm{A}$ as the center, then point $\mathrm{A}$ is identified as one noise point. If there are two or more points in the spherical space, point $A$ is not a noise point. The radius in this study was set to $5 \mathrm{~m}$ based on the empirical value. Building points such as house, electric power, and lines could easily be extracted by visual and manual editing based on their regular shape. The triangulated irregular network (TIN) algorithm was applied to extract ground point clouds. Subsequently, the digital elevation model (DEM) with a resolution of $0.2 \mathrm{~m}$ was generated from ground points using the (TIN) interpolation method [38]. Then, the classified point clouds were normalized by subtracting the DEM in which the noise and building point clouds were excluded to improve the accuracy of the normalized point clouds. The height value of each normalized point equaled the difference value between the height value of 
the original point and the corresponding terrain elevation. DSM with a resolution of $0.2 \mathrm{~m}$ was generated from the ground and vegetation points using the maximum interpolation method [39]. CHM was directly generated by subtracting DEM from DSM. The cell value of the canopy height model (CHM) equaled the difference value between the height value of the highest point within that cell and the corresponding terrain elevation.

To make the results from ULS and USP more comparable, the NPCs of UAV photogrammetry (P-NPC) were created by subtracting the ULS DEM (L-DEM), and then the CHM of photogrammetry (P-CHM) was created by subtracting L-DEM from P-DSM.

In addition, to analyze the impact of point density on the estimated stand heights, we thinned the original density datasets to $0.8,1,5,10$, and $30 \mathrm{pts} / \mathrm{m}^{2}$ using the ThinData model in Fusion software, respectively [40]. The algorithm first figures out the cover area of each input point cloud data, then divides the data into grids with a certain cell size, and identifies the thinned ratio based on the target point cloud density and the pulse density of each grid cell. Finally, the thinning is performed by randomly removing until achieving the desired pulse density. In this study, the certain grid cell size was set to the default value $5 \mathrm{~m} \times 5 \mathrm{~m}$. To evaluate the uncertainty in the thinning process and reduce the random effects from the thinned point clouds, we executed 30 random repetitions for original point cloud datasets to the target density. An example of thinned point clouds can be found in Figures 4 and 5. It can be found from Figure 4 that the thinning algorithm evenly thinned the point clouds. Correspondingly, the vertical distribution profiles did not have significant differences except for lower point densities $\left(0.8 \mathrm{pts} / \mathrm{m}^{2}, 1 \mathrm{pts} / \mathrm{m}^{2}\right)$, as seen in Figure 5 .

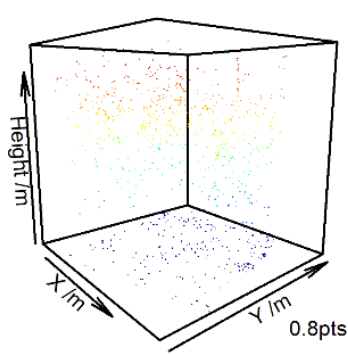

(a1)

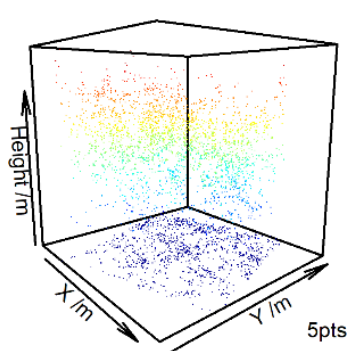

(a2)

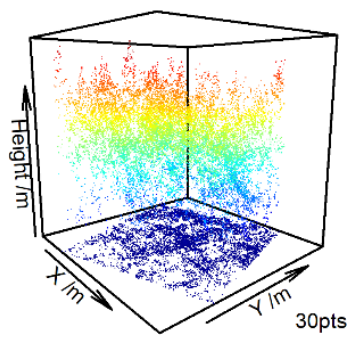

(a3)

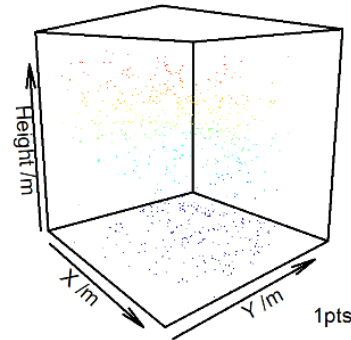

(b1)

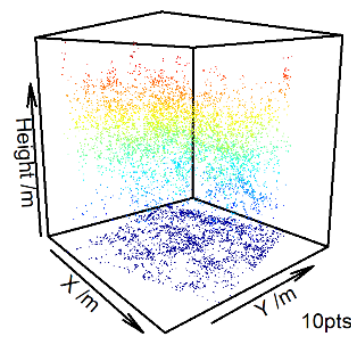

(b2)

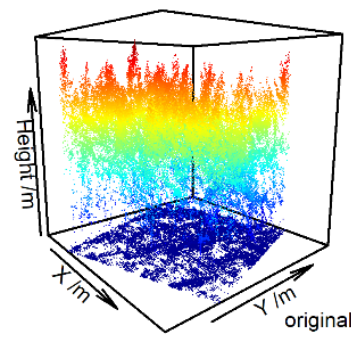

(b3)

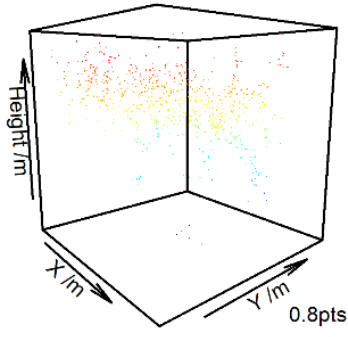

(c1)

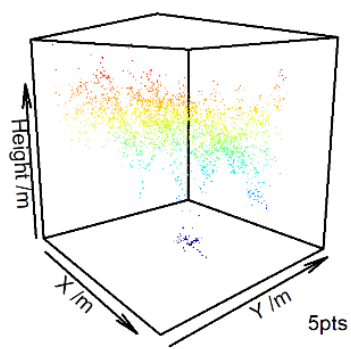

(c2)

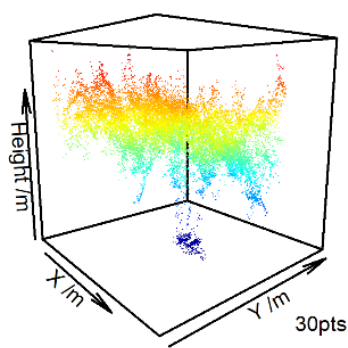

(c3)

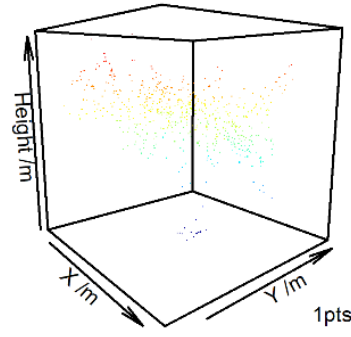

(d1)

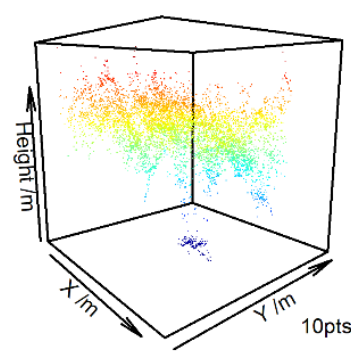

(d2)

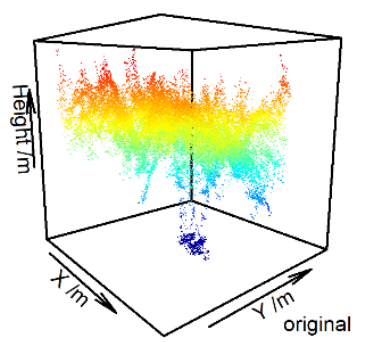

(d3)

Figure 4. An example of thinned datasets with $0.8,1,5,10$, and $30 \mathrm{pts} / \mathrm{m}^{2}$ and original data from ULS (a1-a3,b1-b3) and USP (c1-c3,d1-d3) at plot YD11-1Y. 


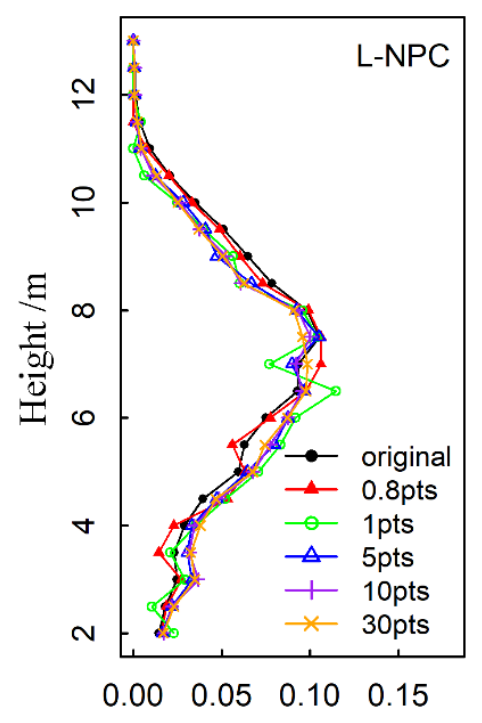

(a)

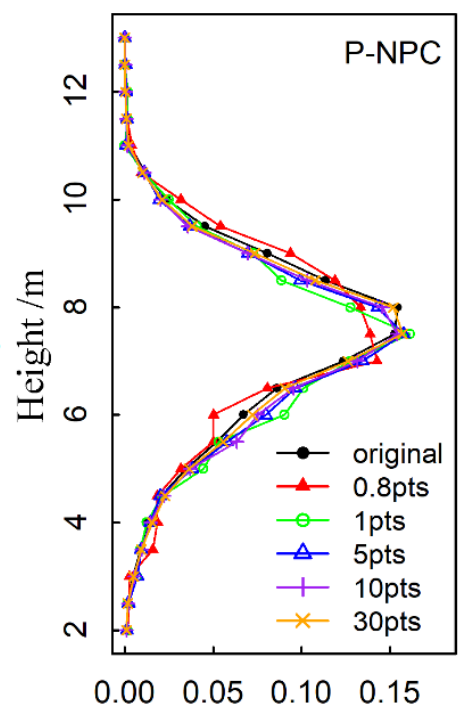

(b)

Figure 5. An example of the vertical distribution curves of thinned datasets with $0.8,1,5,10$, and $30 \mathrm{pts} / \mathrm{m}^{2}$ and original point cloud density data from ULS (a) and USP (b) at plot YD11-1Y.

\subsubsection{Feature Metrics Generation}

The normalized point clouds and CHM of 71 plots from ULS and USP were all clipped out according to their corresponding boundaries. The point clouds or the CHM cells with height $<2 \mathrm{~m}$ were excluded, which were considered as echoes from shrubs, grass, or ground surface rather than from the canopy. For comparison of the performance of ULS and USP in describing vertical distribution and height estimation, the commonly used height metrics and density metrics were both derived from NPC or CHM. In this study, a total of 20 metrics (Table 3) were extracted from L-NPC, P-NPC, L-CHM, and P-CHM respectively, including 10 height percentiles $\left(h_{10}, h_{20}, h_{30}, \ldots, h_{90}\right.$, and $\left.h_{95}\right), 6$ height statistical metrics $\left(h_{\mathrm{max}}, h_{\mathrm{cv}}, h_{\mathrm{sd}}, h_{\text {mean }}, h_{\mathrm{med}}\right.$, and $\left.h_{\mathrm{IQ}}\right)$, and 4 density statistical metrics [41]. The $h_{\mathrm{cv}}$ and $h_{\mathrm{sd}}$ were the coefficients of variation and the standard deviation of heights representing the variation and heterogeneity of forest canopy height. In summary, four datasets including normalized point clouds from ULS and USP (L-NPC, P-NPC), CHM from ULS, and USP (L-CHM and P-CHM) were used in this study.

Table 3. The metrics extracted from normalized point clouds or CHMs.

\begin{tabular}{ccc}
\hline Category & Parameters & Describing \\
\hline Height percentiles & $h_{10}, h_{20}, \ldots, h_{80}, h_{90}, h_{95}$ & Height percentile value for point clouds or CHM cells over $2 \mathrm{~m}$ \\
& $h_{\max }$ & Maximum value for point clouds or CHM cells over $2 \mathrm{~m}$ \\
Height statistical metrics & $h_{\text {mean }}$ & Mean value for point clouds or CHM cells over $2 \mathrm{~m}$ \\
& $h_{\text {med }}$ & Median value for point clouds or CHM cells over $2 \mathrm{~m}$ \\
& $h_{\mathrm{cv}}$ & Coefficient of variation for point clouds or CHM cells over $2 \mathrm{~m}$ \\
& $h_{\mathrm{sd}}$ & Standard deviation for point clouds or CHM cells over $2 \mathrm{~m}$ \\
Density statistical metrics & $h_{\mathrm{IQ}}$ & $\left(h_{\mathrm{m}} \mathrm{minus} h_{25}-h_{\min }\right) /\left(h_{\max }-h_{\mathrm{min}}\right)$ \\
& $C R R$ & Percentage of point cloud above $2 \mathrm{~m}$ \\
& $C C_{2 \mathrm{~m}}$ & Percentage of point cloud above mean \\
& $C C_{\text {mean }}$ & Percentage of point cloud above mode \\
\hline
\end{tabular}

\subsection{Data Analysis}

To have a systematic and comprehensive analysis of ULS and USP, we quantified the spatial distribution of the two data source based on their metrics and compared their performance on the forest common stand height estimation. In detail, two methods were 
used to compare and analyze the differences between the ULS and USP. The first was by comparing the correlation and difference between each pair of metrics from the four datasets such as $h_{10}$ from L-NPC and $h_{10}$ from P-NPC using the Pearson's coefficients $(r)$ and mean difference $(M D)$.

$$
\begin{gathered}
r=\frac{\sum_{i}^{n}\left(l_{i}-\overline{\bar{l}}\right)\left(p_{i}-\overline{\bar{p}}\right)}{\sqrt{\sum_{i}^{n}\left(l_{i}-\overline{\bar{l}}\right)^{2}} \sqrt{\sum_{i}^{n}\left(p_{i}-\overline{\bar{p}}\right)^{2}}} \\
M D=\frac{\sum_{i=1}^{n}\left(l_{i}-p_{i}\right)}{n}
\end{gathered}
$$

where $l_{i}$ is the estimated stand height of $i^{t h}$ from ULS data and $p_{i}$ is the estimated stand height of $i^{\text {th }}$ from USP data.

The second method was to analyze the capability of the four datasets to estimate the forest stand height. In this paper, the simple linear regression was employed to model the forest stand height using metrics. The best metrics with the highest $R^{2}$ from one dataset were extracted as the explanatory variable for modeling simple linear regression. Then, 10 -fold cross validation was applied for estimating the accuracy of each linear regression model using $R^{2}, R M S E$, and $r R M S E$ based on the observed values and the corresponding estimated values. In this study, three forest cases were considered including ALL plots, LYS plots alone, and YS plots alone, respectively. In total, 48 models for original point cloud density and 40 models for five thinned point cloud densities were analyzed in this study.

$$
\begin{gathered}
R^{2}=1-\frac{\sum_{i=1}^{n}\left(y_{i}-\hat{y}_{i}\right)^{2}}{\sum_{i=1}^{n}\left(y_{i}-\bar{y}\right)^{2}} \\
R M S E=\sqrt{\frac{\sum_{i=1}^{n}\left(y_{i}-\hat{y}_{i}\right)^{2}}{n}} \\
r R M S E=\frac{R M S E}{\bar{y}}
\end{gathered}
$$

where $n$ is the number of plots; $y_{i}$ is the measured stand height of $i^{\text {th }}$ plot; $\hat{y}_{i}$ is the predicted stand height of $i^{\text {th }}$ plot; and $\bar{y}$ is the mean of observed stand height.

In addition, to explore the effect of point densities on the estimation accuracy of forest stand heights and analyze the estimation accuracy of ULS and USP data at the same point density level, four stand heights were estimated using the thinned data and the same explanatory variable as the original point density of the ULS and USP data. The predication accuracy was also assessed using $R^{2}, R M S E$, and 10-fold cross validation.

\section{Results}

\subsection{Visual Comparison of ULS Point Clouds and USP Point Clouds}

Based on the CC of all plots, three plots (Table 4) representing three different $\mathrm{CC}$ levels (high CC, median CC, low CC), respectively, were selected to demo and visually compare the differences between ULS and USP point clouds. The height ranges of NPC from USP were mostly consistent with those from ULS. The minimum heights of the NPC were all equal to 0 except for USP NPC within the high CC plot, the maximum heights of P-NPC $(8.59 \mathrm{~m} \sim 17.02 \mathrm{~m})$ were all less than the corresponding L-NPC $(8.65 \mathrm{~m} \sim 17.36 \mathrm{~m})$. 
Table 4. The basic information of three plots with different CC.

\begin{tabular}{cccccccc}
\hline \multirow{2}{*}{ CC Level } & \multirow{2}{*}{ CC } & \multicolumn{3}{c}{ L-NPC } & \multicolumn{3}{c}{ P-NPC } \\
\cline { 3 - 8 } & & pts/m & Minimum & Maximum & pts/m & Minimum & Maximum \\
\hline High CC & 0.92 & 71 & 0 & 17.36 & 47 & 4.65 & 17.02 \\
Median CC & 0.75 & 97 & 0 & 13.21 & 46 & 0 & 13.00 \\
Low CC & 0.49 & 47 & 0 & 8.65 & 44 & 0 & 8.59 \\
\hline
\end{tabular}

From the 3D distribution of point clouds within different CC plots from ULS (Figure 6a1-a3), it can be seen that there were more and more point clouds hitting the ground with the decreasing CC for ULS. In contrast, there were no corresponding changes and there were obviously less point clouds from the understory and ground for USP point clouds (Figure 6b1-b3), even for the plot with low $C C=0.49$. In addition, the extracted ground point clouds from USP mostly gathered together where there was a big gap between crowns. It can be seen from the profiles of the original point clouds (Figure $6 \mathrm{c} 1-\mathrm{c} 3$ ) and normalized point cloud (Figure 6d1-d3) that the point clouds generated from USP were mostly located around the canopy surface, and had high coincidence with the point clouds extracted from ULS, except for some point clouds from tree tops. The different distribution of USP dense point clouds and ULS under the canopy was subjected to the different principles of the two data sources. The USP did not have the ability to penetrate the canopy, which is the difference from ULS.

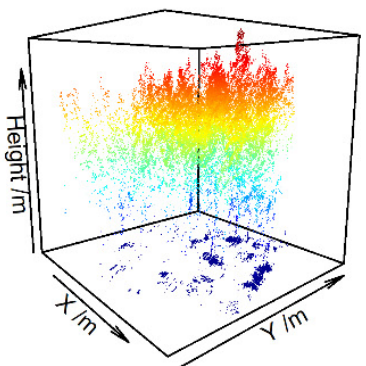

(a1)

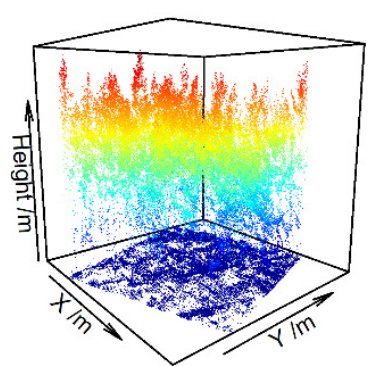

(a2)

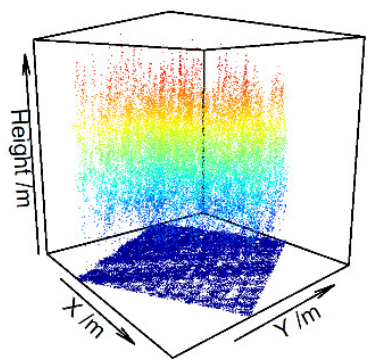

(a3)

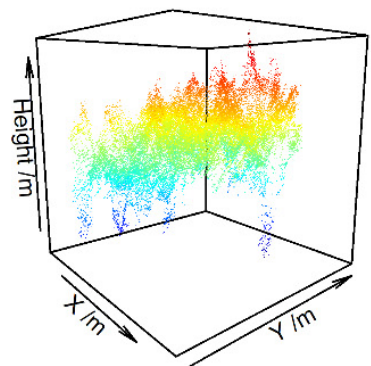

(b1)

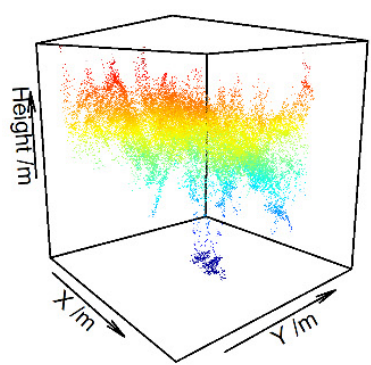

(b2)

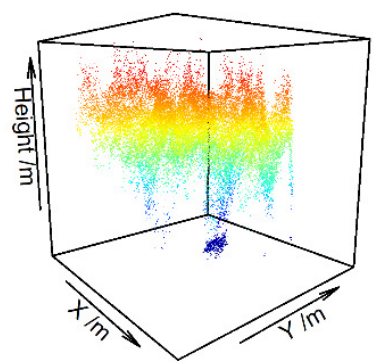

(b3)

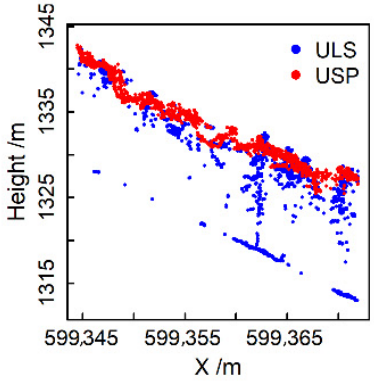

(c1)

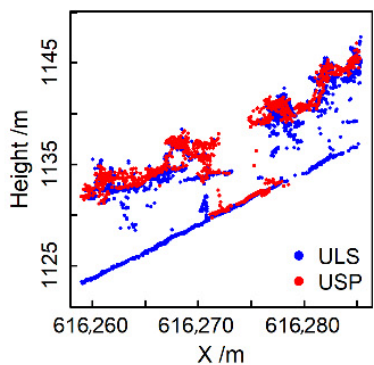

$(\mathrm{c} 2)$

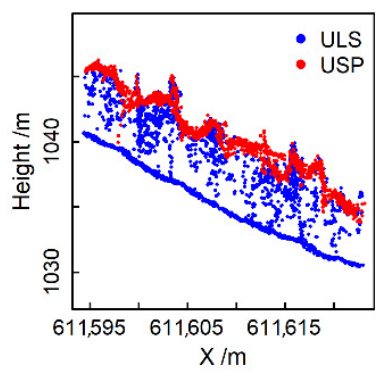

(c3)

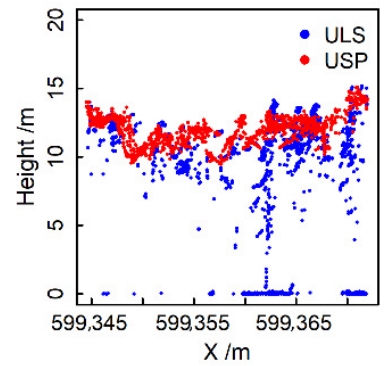

(d1)

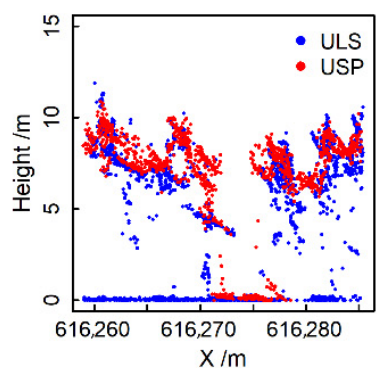

(d2)

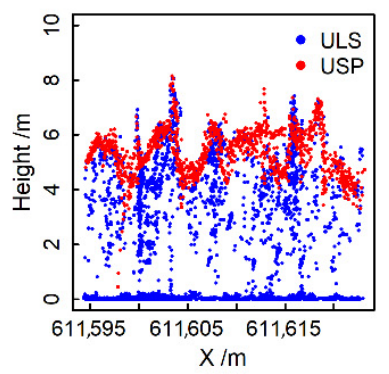

(d3)

Figure 6. Comparison of the ULS point clouds and USP point clouds within different CC. 3D distribution of ULS point clouds (a1-a3), 3D distribution of USP point clouds (b1-b3), the original point cloud profile within a transect of $1 \mathrm{~m}$ width (c1-c3), and the normalized point cloud profile within a transect of $1 \mathrm{~m}$ width (d1-d3). 


\subsection{Forest Stand Heights Modeling Using ULS and USP Metrics}

The correlations between forest stand heights and height metrics from L-NPC, L-CHM, P-NPC, and P-CHM are shown in Figure 7a1,a2,b1,b2 and Figure 8a1,a2,b1,b2, respectively, from which we could find that the correlations between NPC or CHM metrics from USP (Figure 8) and forest stand heights were consistent with the corresponding metrics from ULS (Figure 7). Overall, each forest height had strong correlation with height percentiles $\left(h_{10} \sim h_{95}\right), h_{\text {med }}$ and $h_{\text {mean }}$, and less correlation with height statistical metrics $h_{\mathrm{cv}}, h_{\mathrm{sd}}$, and $h_{\mathrm{IQ}}$ with $R^{2}$ ranging from 0.006 to 0.460 and $R M S E$ varying from 10.015 to $13.06 \mathrm{~m}$.

The $R^{2}$ and RMSE of height percentiles $\left(h_{10} \sim h_{95}\right), h_{\text {med }}, h_{\text {mean }}$, and forest stand heights ranged from 0.734 to $0.944,0.861 \mathrm{~m}$ to $7.681 \mathrm{~m}$ for L-NPC, respectively, and from 0.735 to $0.952,0.822 \mathrm{~m}$ to $7.518 \mathrm{~m}$ for L-CHM, respectively. Like with the USP data, the $R^{2}$ and RMSE of the height metrics ranged from 0.800 to $0.942,0.890 \mathrm{~m}$ to $5.517 \mathrm{~m}$ for the NPC metrics, respectively, and from 0.795 to $0.942,0.868 \mathrm{~m}$ to $5.463 \mathrm{~m}$ for the CHM metrics, respectively.

$H_{A}$ and $H_{\text {Med }}$ had a higher correlation with the lower height percentiles $\left(h_{30}, h_{40}\right), h_{\text {med }}$ and $h_{\text {mean }}$, while $H_{L}$ and $H_{\text {Dom }}$ had a higher correlation with the upper height percentiles such as $h_{80}$ and $h_{90}$.

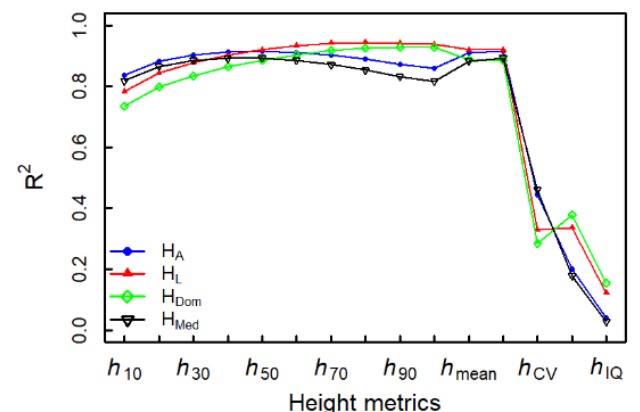

(a1)

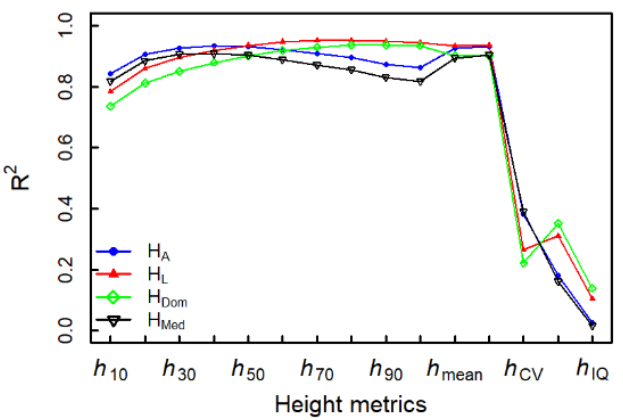

(a2)

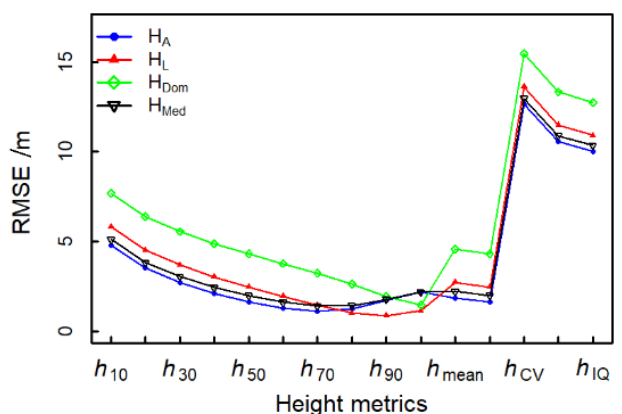

(b1)

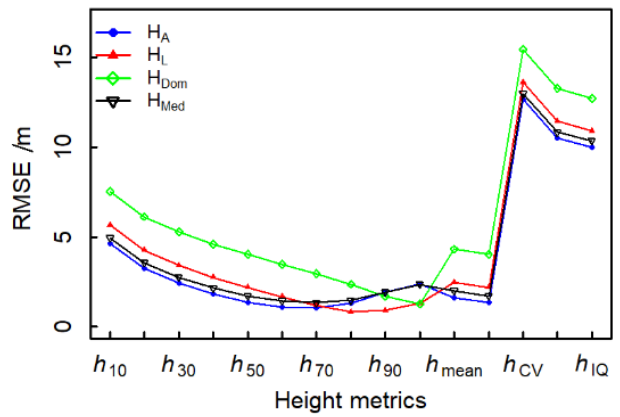

(b2)

Figure 7. Correlation between the stand heights and height metrics calculated from the L-NPC metrics $(\mathbf{a} 1, \mathbf{b} 1)$ and L-CHM metrics $(\mathbf{a} 2, \mathbf{b} 2)$ for ALL plots. 


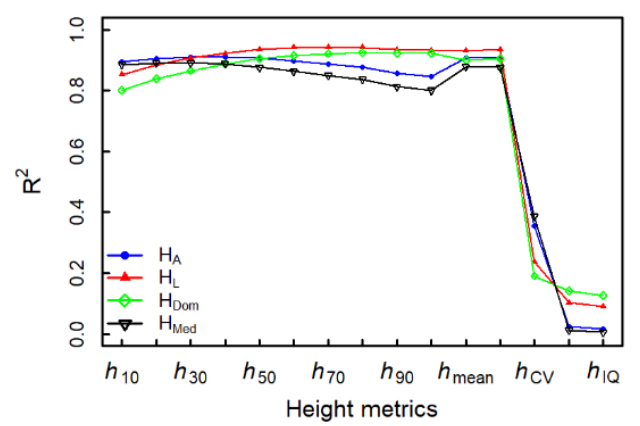

(al)

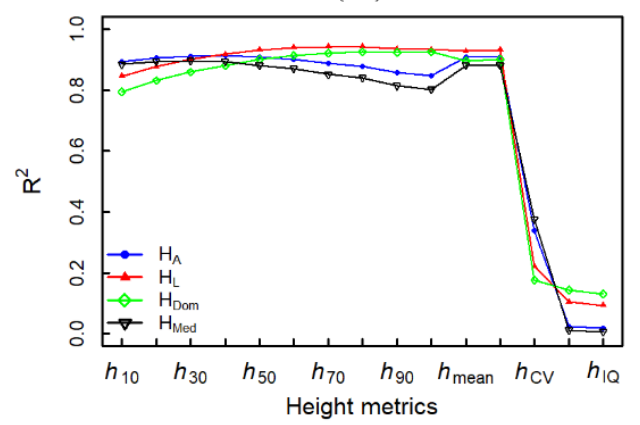

(a2)

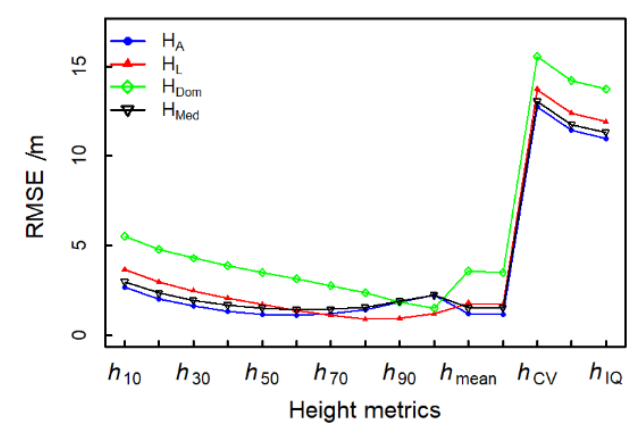

(b1)

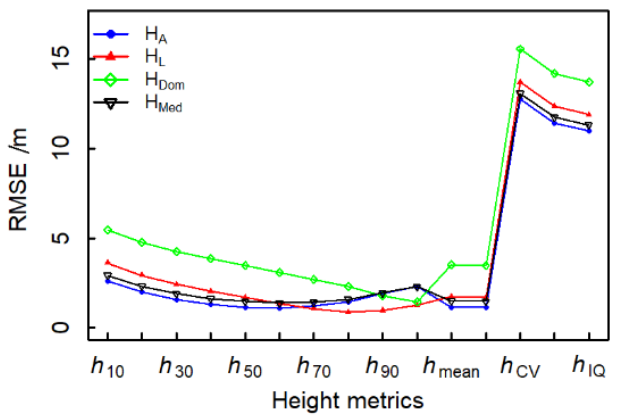

(b2)

Figure 8. Correlation between the stand heights and height metrics calculated from the P-NPC metrics $(\mathbf{a} 1, \mathbf{b} 1)$ and P-CHM metrics $(\mathbf{a} 2, \mathbf{b} 2)$ for ALL plots.

Based on the strong correlations between height metrics and each forest stand height, simple linear regression for $H_{A}, H_{L}, H_{D o m}$, and $H_{\text {Med }}$ using height metrics generated from the ULS and USP datasets was applied to fit each forest stand height. The best explanatory variables for different models, and corresponding modeling accuracy of simple linear regression models using NPC and CHM metrics alone extracted from ULS and USP, respectively, are summarized in Figure 9 and Table 5.

Compared with the best explanatory variables obtained from L-NPC, the explanatory variables obtained from P-NPC mostly took the lower height percentiles. For instance, $h_{80}$, $h_{90}$, and $h_{80}$ of L-NPC were the best explanatory variables for $H_{L}$ in the corresponding forest types (ALL plots, LYS plots, and YS plots, respectively), while $h_{70}, h_{80}$, and $h_{60}$ obtained from P-NPC were the corresponding best explanatory variables for $H_{L}$. This tendency was also obvious for CHM metrics.

From Figure 9, it can also be seen that the best explanatory variables for the four forest stand heights modeled from P-NPC and P-CHM metrics were basically the same, except for the $H_{\text {Dom }}$ of LYS plots, while the best explanatory variables from L-NPC metrics were higher or the same as that from the L-CHM metrics.

The best explanatory variables varied with different stand heights from lower height percentiles to upper height percentiles. In an item of $H_{L}$ and $H_{\text {Dom }}$, their best explanatory variables were mostly the upper height percentiles such as $h_{80}, h_{90}$, and $h_{95}$, while the lower and median height percentiles were the best independent variables for $H_{A}$ and $H_{\text {Med }}$ such as $h_{30}, h_{40}, h_{50}$, and $h_{60}$. For different forest types, the best explanatory variables for the same stand height varied within a certain range. The best independent variables for forest stand heights from the LYS plots were higher than those of the YS plots. For example, for $H_{A}, H_{L}, H_{D o m}$, and $H_{\text {Med }}$ modeled from the L-NPC metrics, their corresponding best variables $h_{60}, h_{90}, h_{95}$, and $h_{70}$ from the LYS plots were higher than $h_{40}, h_{80}, h_{90}$, and $h_{30}$ from the YS plots, respectively. 


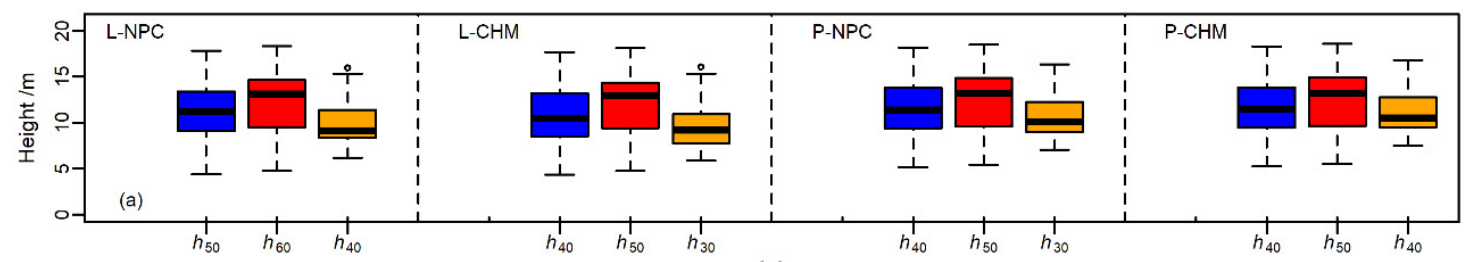

(a)

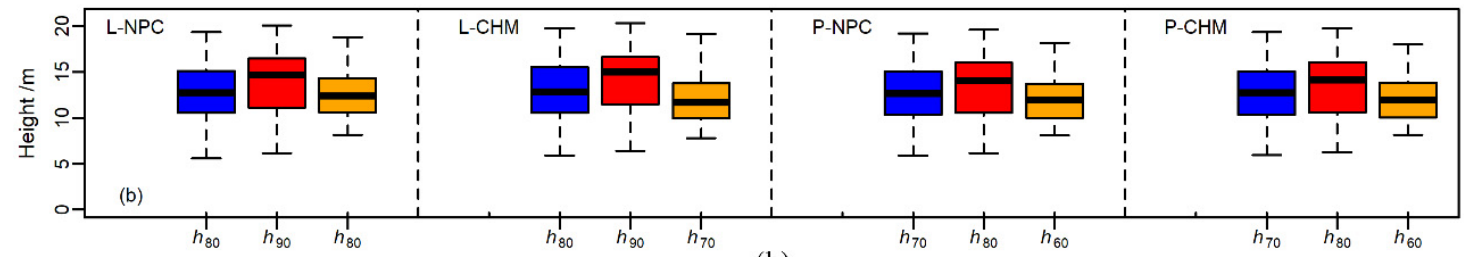

(b)

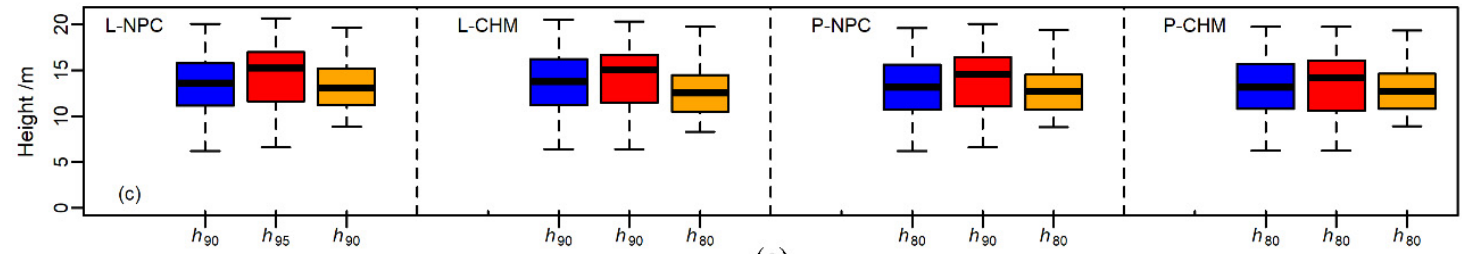

(c)

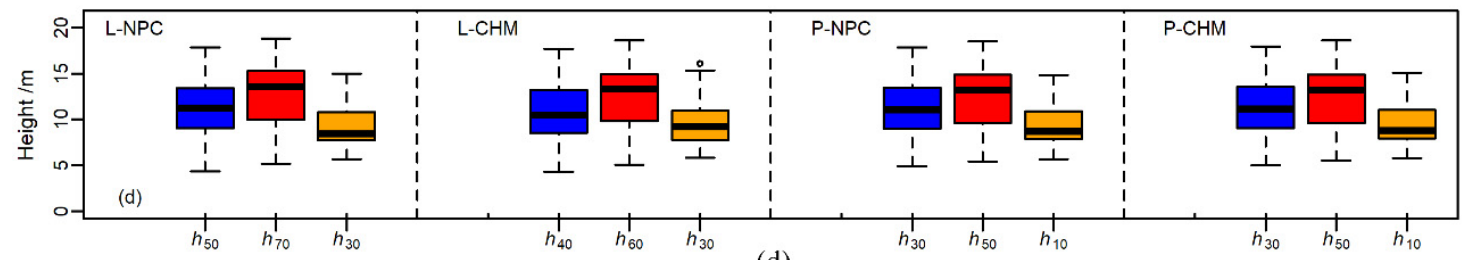

(d)

Figure 9. The boxplots of the best explanatories for each stand height modeled by L-NPC, L-CHM, P-NPC, and P-CHM alone. (a) Mean height, (b) Lorey's height, (c) dominated height, and (d) median height.

Table 5. The accuracy assessments of the four stand height predictive models from the ULS and USP metrics.

\begin{tabular}{|c|c|c|c|c|c|c|c|c|c|c|}
\hline \multirow[b]{2}{*}{ Data Type } & \multirow[b]{2}{*}{ Stand Height } & \multicolumn{3}{|c|}{ ALL Plots } & \multicolumn{3}{|c|}{ LYS Plots } & \multicolumn{3}{|c|}{ YS Plots } \\
\hline & & $R^{2}$ & $\begin{array}{c}\text { RMSE } \\
/ \mathrm{m}\end{array}$ & $\begin{array}{c}r R M S E \\
\%\end{array}$ & $R^{2}$ & $\begin{array}{c}\text { RMSE } \\
/ \mathrm{m}\end{array}$ & $\begin{array}{c}r R M S E \\
\%\end{array}$ & $R^{2}$ & $\begin{array}{c}\text { RMSE } \\
/ \mathrm{m}\end{array}$ & $\begin{array}{c}\text { rRMSE } \\
\%\end{array}$ \\
\hline \multirow{4}{*}{ L-NPC } & $H_{A}$ & 0.91 & 1.01 & 8.16 & 0.94 & 0.93 & 7.14 & 0.92 & 0.92 & 7.70 \\
\hline & $H_{L}$ & 0.94 & 0.82 & 6.14 & 0.96 & 0.78 & 5.66 & 0.94 & 0.79 & 6.03 \\
\hline & $H_{\text {Dom }}$ & 0.93 & 0.98 & 6.45 & 0.95 & 0.88 & 5.71 & 0.91 & 1.01 & 6.75 \\
\hline & $H_{M e d}$ & 0.89 & 1.21 & 9.53 & 0.91 & 0.98 & 7.39 & 0.89 & 1.12 & 9.20 \\
\hline \multirow{4}{*}{ L-CHM } & $H_{A}$ & 0.93 & 0.90 & 7.27 & 0.94 & 0.91 & 6.98 & 0.92 & 0.88 & 7.40 \\
\hline & $H_{L}$ & 0.95 & 0.76 & 5.66 & 0.96 & 0.75 & 5.47 & 0.94 & 0.81 & 6.18 \\
\hline & $H_{\text {Dom }}$ & 0.94 & 0.93 & 6.08 & 0.96 & 0.82 & 5.33 & 0.91 & 0.99 & 6.58 \\
\hline & $H_{\text {Med }}$ & 0.91 & 1.11 & 8.78 & 0.93 & 1.04 & 7.79 & 0.84 & 1.38 & 11.3 \\
\hline \multirow{4}{*}{ P-NPC } & $H_{A}$ & 0.91 & 1.04 & 8.37 & 0.94 & 0.87 & 6.71 & 0.9 & 1.02 & 8.56 \\
\hline & $H_{L}$ & 0.94 & 0.83 & 6.23 & 0.96 & 0.74 & 5.36 & 0.93 & 0.84 & 6.39 \\
\hline & $H_{D o m}^{L}$ & 0.92 & 1.01 & 6.63 & 0.95 & 0.85 & 5.53 & 0.90 & 1.07 & 7.08 \\
\hline & $H_{M e d}$ & 0.89 & 1.21 & 9.55 & 0.95 & 0.88 & 6.62 & 0.88 & 1.2 & 9.86 \\
\hline \multirow{4}{*}{ P-CHM } & $H_{A}$ & 0.91 & 1.02 & 8.23 & 0.94 & 0.88 & 6.75 & 0.89 & 1.07 & 8.98 \\
\hline & $H_{L}$ & 0.94 & 0.83 & 6.22 & 0.96 & 0.76 & 5.56 & 0.93 & 0.86 & 6.54 \\
\hline & $H_{\text {Dom }}$ & 0.92 & 1.01 & 6.60 & 0.95 & 0.85 & 5.51 & 0.90 & 1.05 & 6.98 \\
\hline & $H_{M e d}$ & 0.90 & 1.18 & 9.36 & 0.93 & 1.03 & 7.78 & 0.83 & 1.42 & 11.64 \\
\hline
\end{tabular}




\subsection{Forest Stand Height Estimation Accuracy}

Figure 10 shows the scatterplots of the estimated stand heights using 10-fold cross validation with L-NPC and L-CHM metrics alone. Overall, the L-NPC and L-CHM metrics both performed best for estimating the forest stand heights with $R^{2}=0.88 \sim 0.96$, $R M S E=0.77 \sim 1.23 \mathrm{~m}$, and $r R M S E=5.69 \sim 9.72 \%$. The performances of the L-CHM metrics models were slightly higher than the results of L-NPC $\left(\Delta R^{2}=0 \sim 0.01, \triangle R M S E=-0.08 \sim 0 \mathrm{~m}\right.$, $\triangle r R M S E=-0.61 \sim 0.05 \%)$.

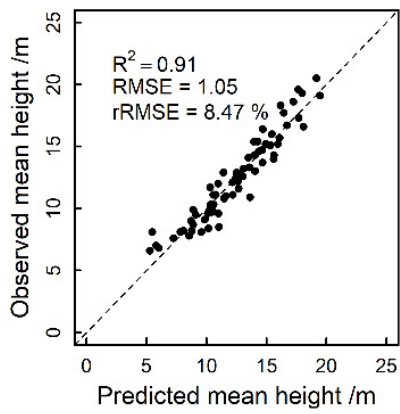

(a1)

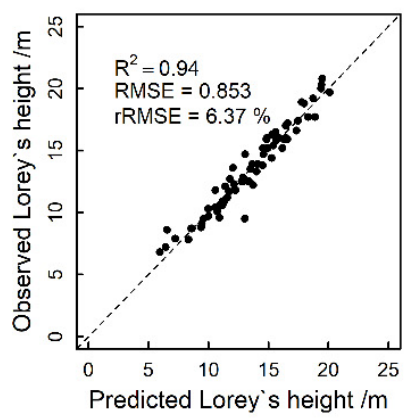

(a2)

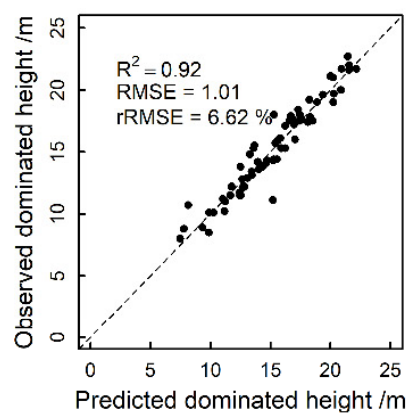

(a3)

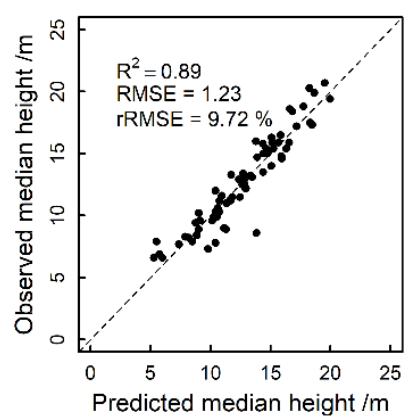

(a4)

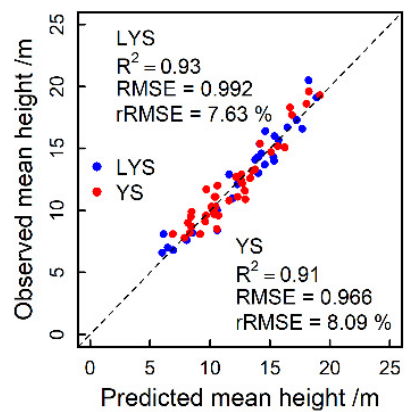

(b1)

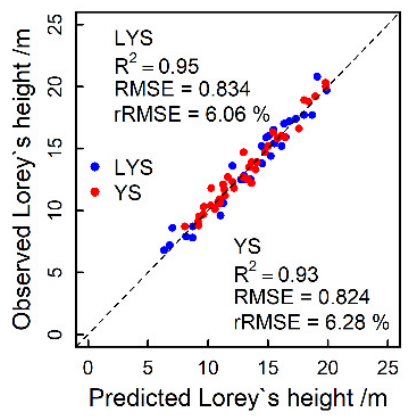

(b2)

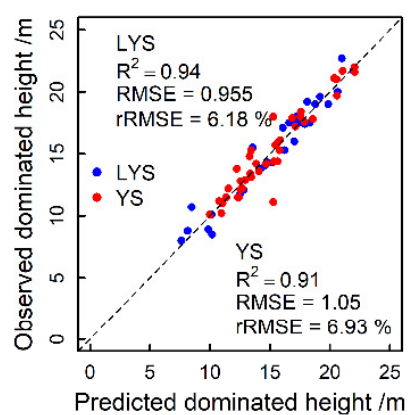

(b3)

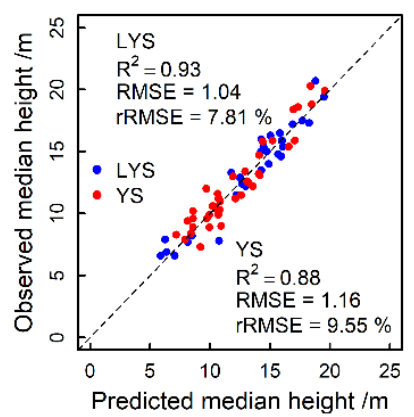

(b4)

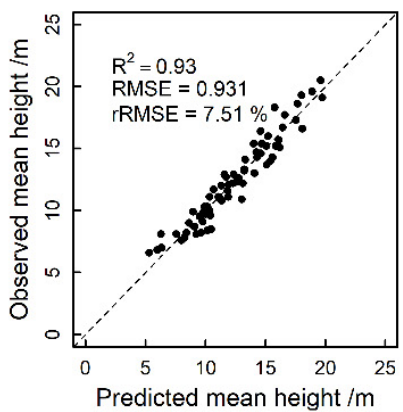

(c1)

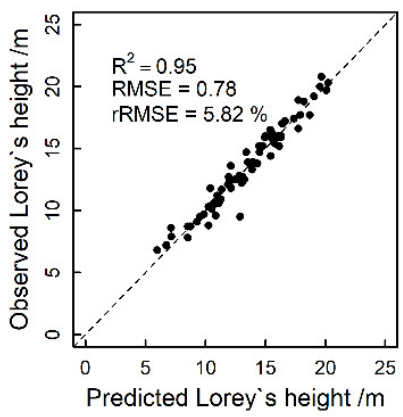

(c2)

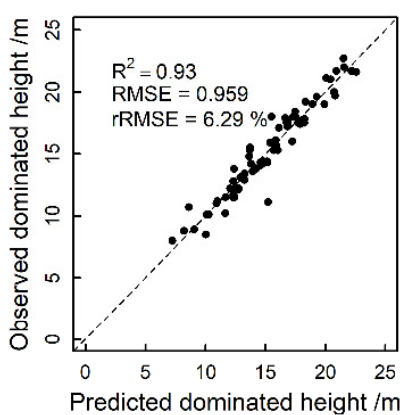

(c3)

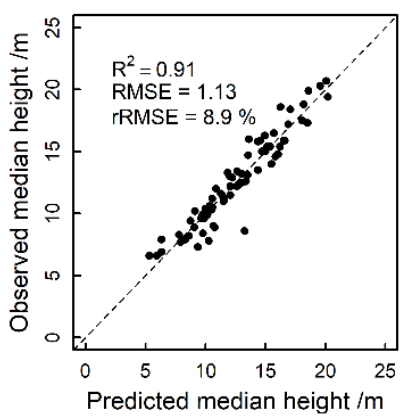

(c4)

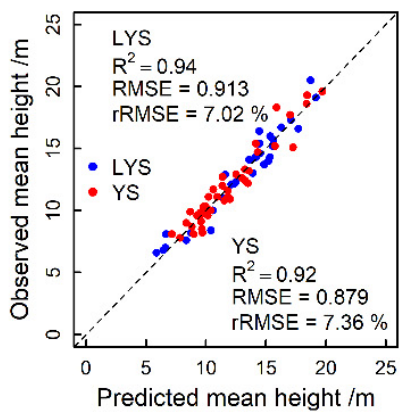

(d1)

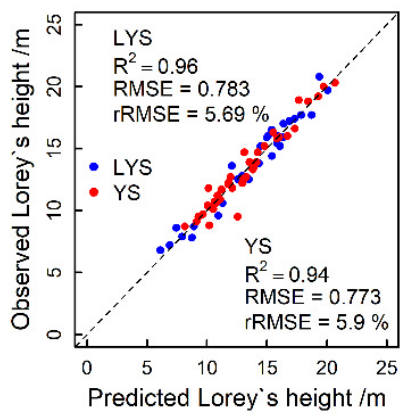

(d2)

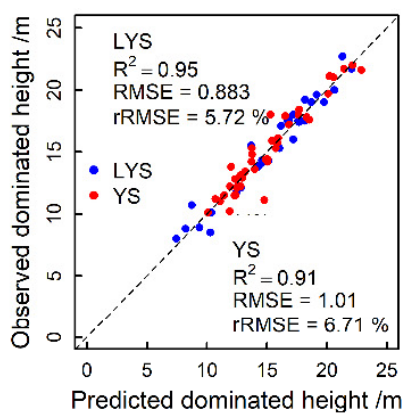

(d3)

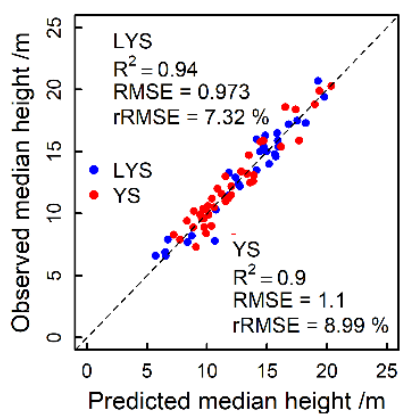

(d4)

Figure 10. Scatterplots of estimated forest stand height and field measured height using ULS metrics. (a1-a4,b1-b4) for L-NPC. (c1-c4,d1-d4) for L-CHM. 
The L-NPC model results showed that the estimation accuracy of $H_{L}$ had the highest accuracy with $R^{2}=0.93 \sim 0.95, R M S E=0.82 \sim 0.85 \mathrm{~m}$, and $r R M S E=6.06 \sim 6.37 \% . H_{D o m}$ had a higher accuracy with $R^{2}=0.91 \sim 0.94, R M S E=0.96 \sim 1.05 \mathrm{~m}$, and $r R M S E=6.18 \sim 6.93 \%$, followed by $H_{A}$ with $R^{2}=0.91 \sim 0.93, R M S E=0.97 \sim 1.05 \mathrm{~m}$, and $r R M S E=7.63 \sim 8.47 \%$, and $H_{M e d}$ had the lowest accuracy $\left(R^{2}=0.88 \sim 0.93, R M S E=1.04 \sim 1.23 \mathrm{~m}\right.$, and $\left.r R M S E=7.81 \sim 9.72 \%\right)$. Compared with the accuracies from the L-NPC models, the results from the L-CHM models showed a similar tendency, where $H_{L}$ had the highest accuracy with $R^{2}=0.94 \sim 0.96$, $R M S E=0.77 \sim 0.78 \mathrm{~m}$, and $r R M S E=5.69 \sim 5.90 \%$, followed by $H_{\text {Dom }}$ with $R^{2}=0.91 \sim 0.95$, $R M S E=0.88 \sim 1.01 \mathrm{~m}$, and $r R M S E=5.72 \sim 6.71 \%$, and $H_{A}$ with $R^{2}=0.92 \sim 0.94, R M S E=0.88 \sim 0.93 \mathrm{~m}$, and $r R M S E=7.02 \sim 7.51 \% . H_{M e d}$ had the lowest accuracy $\left(R^{2}=0.90 \sim 0.94, R M S E=0.97 \sim 1.13 \mathrm{~m}\right.$, and $r R M S E=7.32 \sim 8.99 \%$ ).

As for different forest cases, the estimation accuracy of the four stand heights from the LYS plot alone $\left(R^{2}=0.93 \sim 0.96, R M S E=0.78 \sim 1.04 \mathrm{~m}\right.$ and $\left.r R M S E=5.72 \sim 7.81 \%\right)$ performed better than those of the YS plots alone $\left(\Delta R^{2}=0.02 \sim 0.05, \triangle R M S E=-0.13 \sim 0.03 \mathrm{~m}\right.$, $\triangle r R M S E=-1.74 \sim 0.21 \%)$ and those of the ALL plots $\left(\Delta R^{2}=0.01 \sim 0.04, \triangle R M S E=-0.19 \sim 0 \mathrm{~m}\right.$, $\triangle r R M S E=-1.91 \sim-0.13 \%)$.

The scatterplots of the estimated stand heights using the best explanatory variables from the P-NPC and P-CHM metrics, respectively, are exhibited in Figure 11, from which it can be found that the P-NPC and P-CHM metrics both performed best for estimating forest stand heights with $R^{2}=0.87 \sim 0.96, R M S E=0.78 \sim 1.25 \mathrm{~m}$, and $r R M S E=5.69 \sim 10.3 \%$. The performances of the P-CHM metrics models were mostly consistent with the results of P-NPC $\left(\triangle R^{2}=0 \sim 0.01, \triangle R M S E=-0.03 \sim 0.04 \mathrm{~m}\right.$, and $\left.\triangle r R M S E=-0.28 \sim 0.07 \%\right)$.

Regarding different stand heights, $H_{L}$ still had the highest accuracy with $R^{2}=0.93 \sim 0.96$, $R M S E=0.78 \sim 0.86 \mathrm{~m}$, and rRMSE $=5.69 \sim 6.56 \%$, followed by $H_{\text {Dom }}\left(R^{2}=0.89 \sim 0.95\right.$, $R M S E=0.92 \sim 1.11 \mathrm{~m}$, and $r R M S E=5.92 \sim 7.37 \%)$ and $H_{A}\left(\mathrm{R}^{2}=0.89 \sim 0.94, R M S E=0.93 \sim 1.07\right.$ $\mathrm{m}$, and $r R M S E=7.13 \sim 8.91 \%$ ), and $H_{M e d}$ still had the lowest accuracy with $R^{2}=0.87 \sim 0.94$, RMSE $=0.87 \sim 1.25 \mathrm{~m}$, and $r R M S E=6.98 \sim 10.3 \%$.

For different forest cases, the LYS plots still had a better performance $\left(R^{2}=0.94 \sim 0.96\right.$, RMSE $=0.78 \sim 0.94 \mathrm{~m}$, and $r R M S E=5.69 \sim 7.17 \%)$ than the ALL plots $\left(R^{2}=0.89 \sim 0.94\right.$, RMSE $=0.86 \sim 1.23 \mathrm{~m}$, and $r R M S E=6.4 \sim 9.76 \%)$ and $\mathrm{YS}$ plots $\left(R^{2}=0.87 \sim 0.93\right.$, $R M S E=0.86 \sim 1.25 \mathrm{~m}$, and $r R M S E=6.53 \sim 10.3 \%$ ).

In addition, compared with the ULS results (Figure 10) $\left(R^{2}=0.88 \sim 0.96, R M S E=\right.$ $0.77 \sim 1.23 \mathrm{~m}$, and $r R M S E=5.69 \sim 9.72 \%)$, USP showed a similar performance $\left(R^{2}=0.87 \sim 0.96\right.$, $R M S E=0.78 \sim 1.25 \mathrm{~m}$, and $r R M S E=5.69 \sim 10.3 \%$ ) (Figure 11). Among the results of the 10-fold cross validation from four datasets, L-CHM had the highest accuracy with $R^{2}=0.9 \sim 0.96, R M S E=0.78 \sim 1.13 \mathrm{~m}$, and $r R M S E=5.69 \sim 8.99 \%$ than L-NPC with $\Delta R^{2}=0 \sim 0.02$, $\triangle R M S E=-0.12 \sim-0.04 \mathrm{~m}$, and $\triangle r R M S E=-1.91 \sim-0.22 \%, \mathrm{P}-\mathrm{NPC}$ with $\Delta R^{2}=0 \sim 0.03$, $\triangle R M S E=-0.15 \sim 0 \mathrm{~m}$, and $\triangle r R M S E=-1.55 \sim 0 \%$, and P-CHM with $\Delta R^{2}=0 \sim 0.03, \triangle R M S E$ $=-0.18 \sim-0.01 \mathrm{~m}$, and $\triangle r R M S E=-1.53 \sim-0.07 \%$.

\subsection{Estimation Results of Forest Stand Heights with Different Point Density}

The influence of point density on the estimation accuracy of the four forest stand heights using L-NPC and P-NPC metrics alone are shown in Figure 12. It can be found that the estimation accuracy of each forest stand height was little affected by point density, slightly increased with the point density changing from $0.8 \mathrm{pts}$ to $30 \mathrm{pts} / \mathrm{m}^{2}$, and became more stable, which could also be found from the corresponding RMSE results. As such, mean $R^{2}$ varied from $0.933( \pm 0.002)$ to $0.935( \pm 0)$ with increasing point density for $H_{A}$ using the L-NPC data, and from $0.923( \pm 0.002)$ to $0.931( \pm 0)$ with increasing point density for $H_{A}$ using the P-NPC data. Mean RMSE varied from $1.040( \pm 0.015)$ to $1.036( \pm 0.003)$ with increasing point density for $H_{A}$ using the L-NPC data, and from $1.056( \pm 0.014)$ to $1.037( \pm 0.001)$ with increasing point density for $H_{A}$ using the P-NPC data.

In addition, the estimation accuracy of the four forest stand heights modeled by LNPC metrics was slightly better than those of USP, except for $H_{M e d}$ (Figure 12a4,b4). The 
$H_{\text {Med }}$ estimated using USP was higher than ULS. $H_{\text {Dom }}$ exhibited the least variation with increasing point density (Figure 12a3,b3).

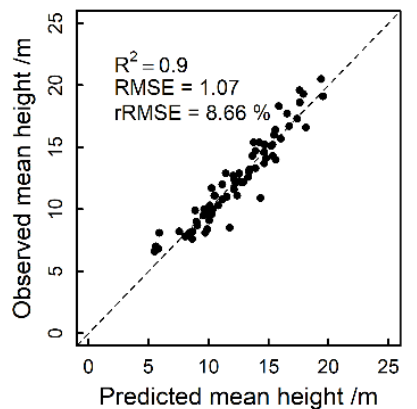

(al)

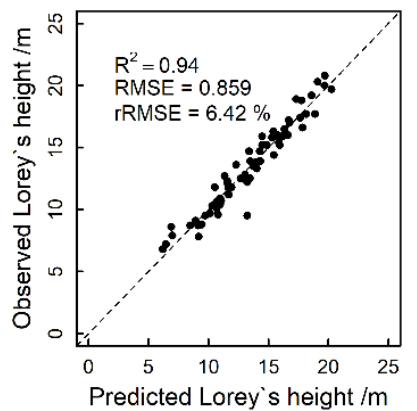

(a2)

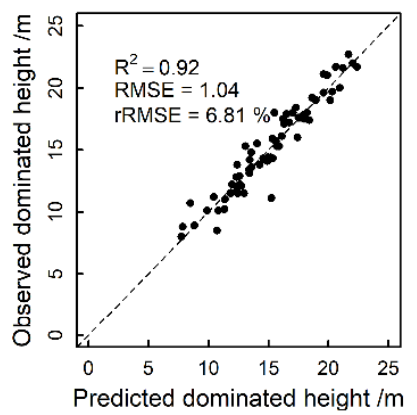

(a3)

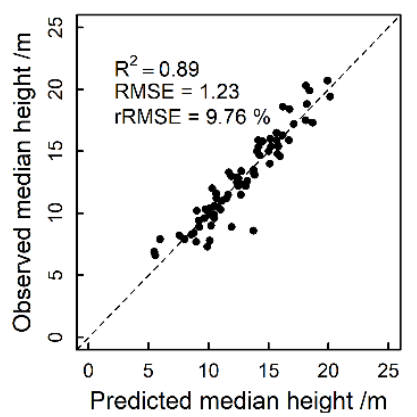

(a4)

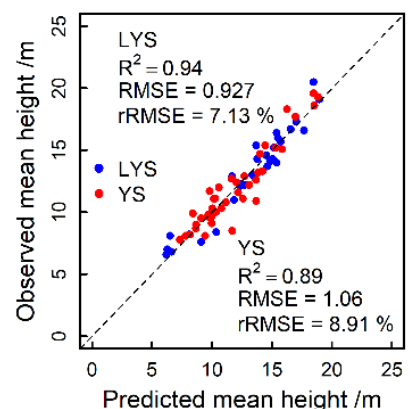

(b1)

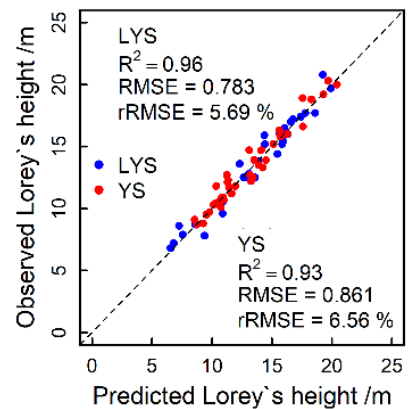

(b2)

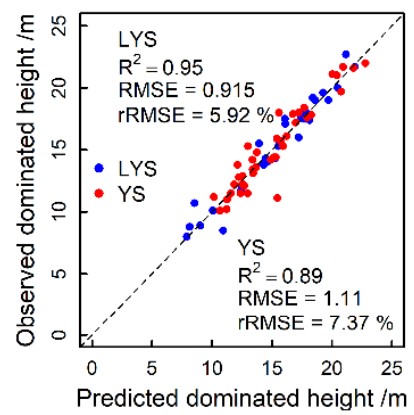

(b3)

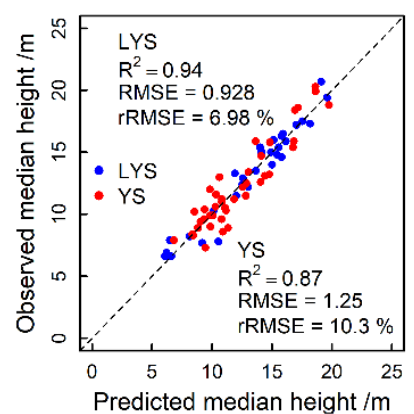

(b4)

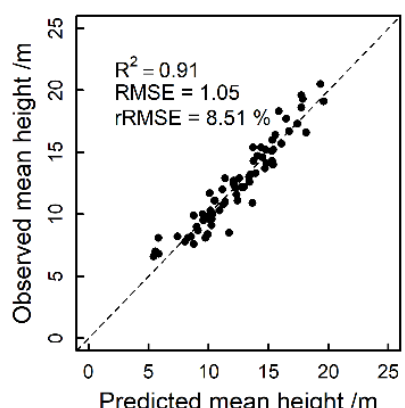

(c1)

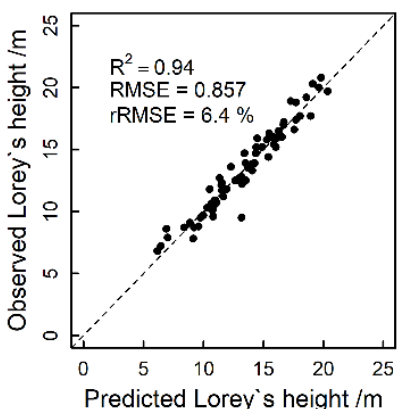

(c2)

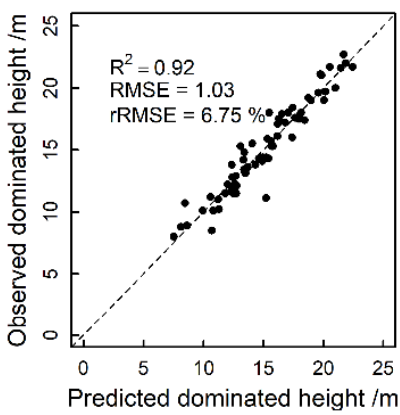

(c3)

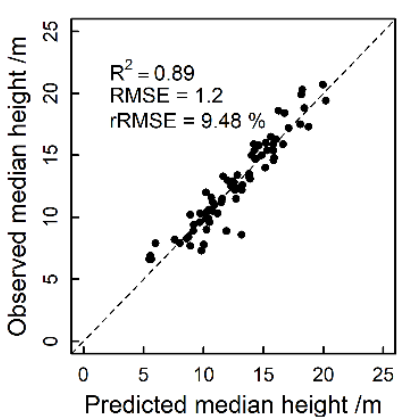

(c4)

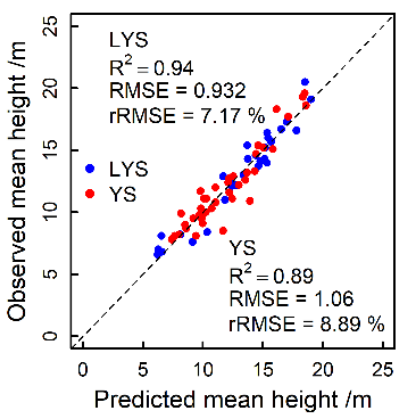

(d1)

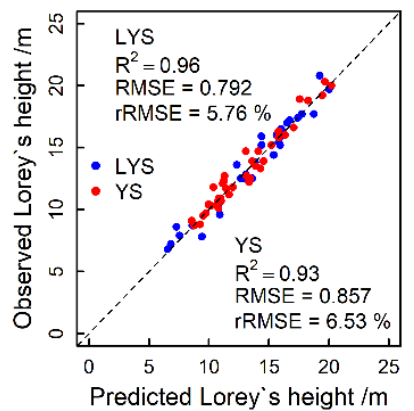

$(\mathrm{d} 2)$

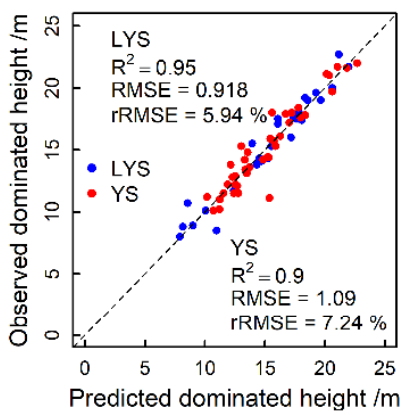

(d3)

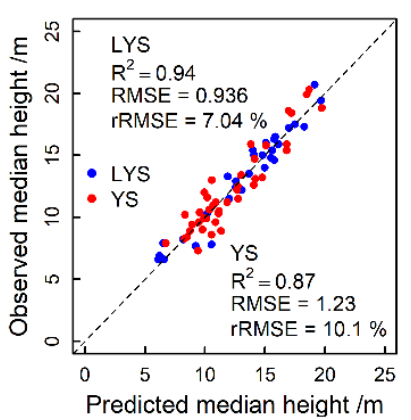

(d4)

Figure 11. The scatterplot of estimated forest stand height and field measured height using USP metrics. (a1-a4,b1-b4) for P-NPC. (c1-c4,d1-d4) for P-CHM. 


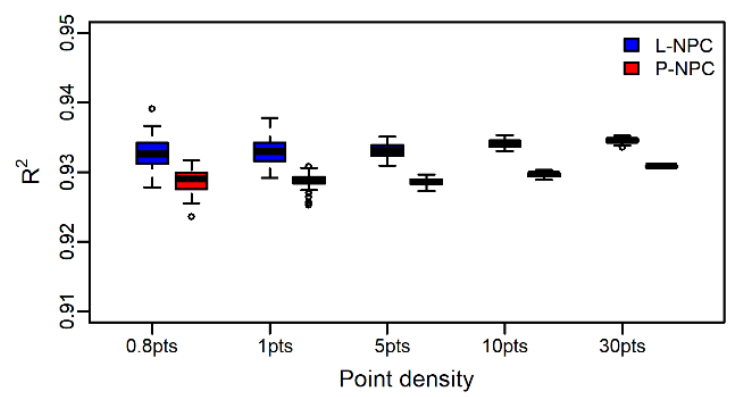

(a1)

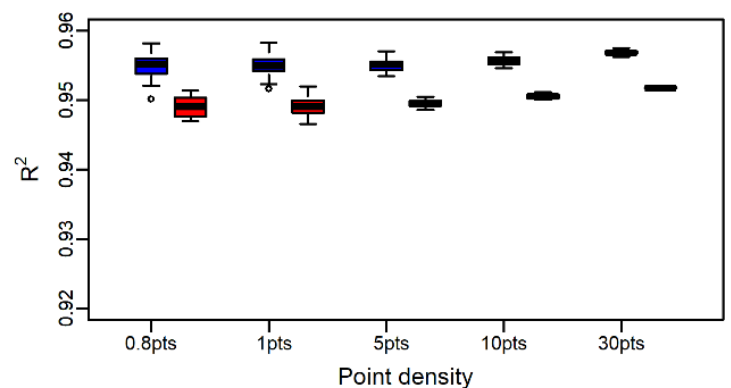

(a2)

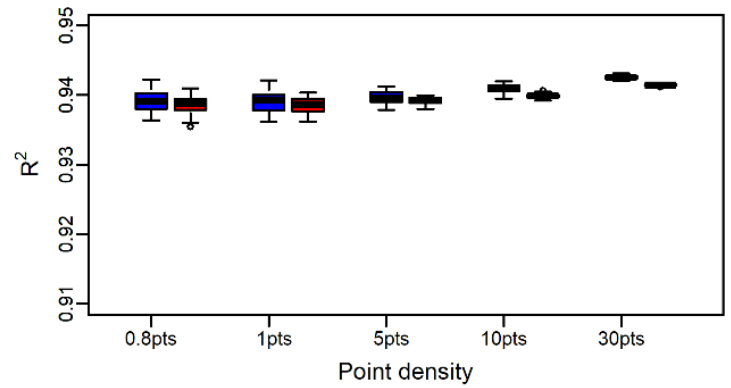

(a3)

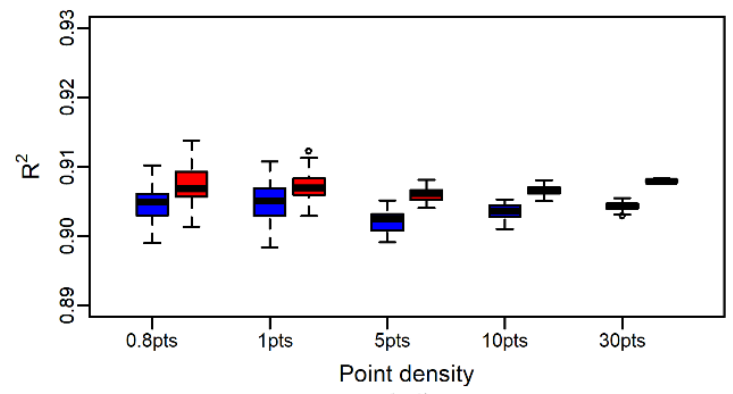

(a4)

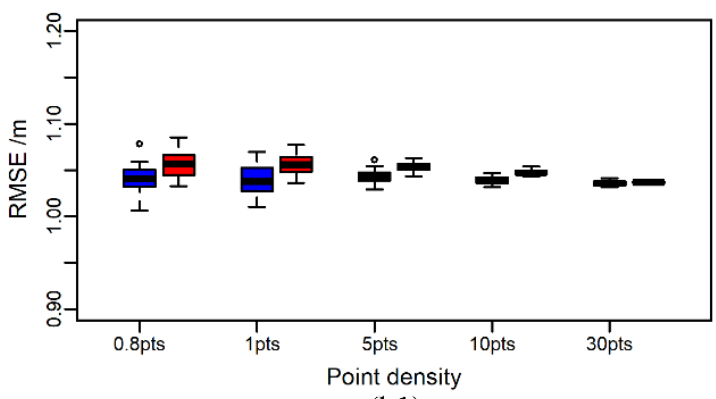

(b1)

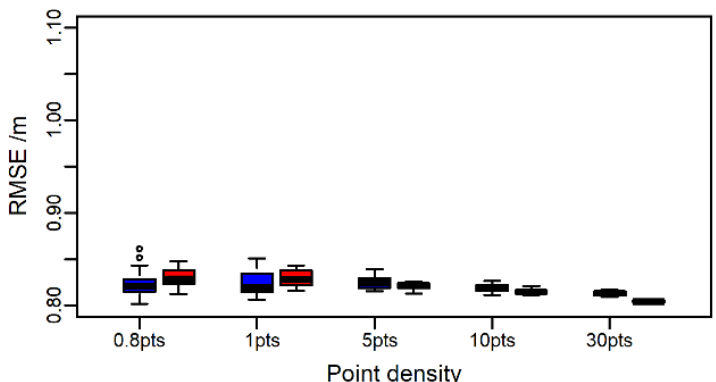

(b2)

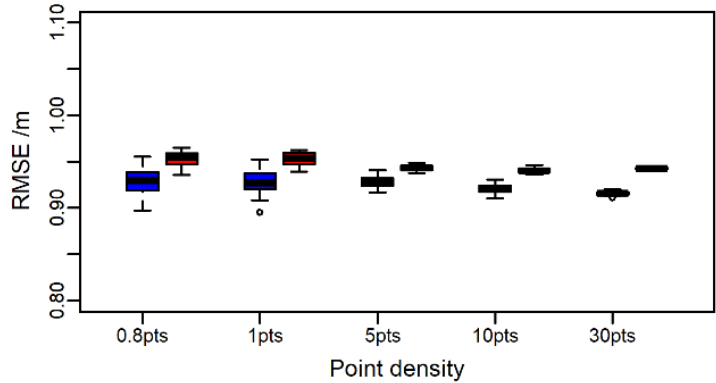

(b3)

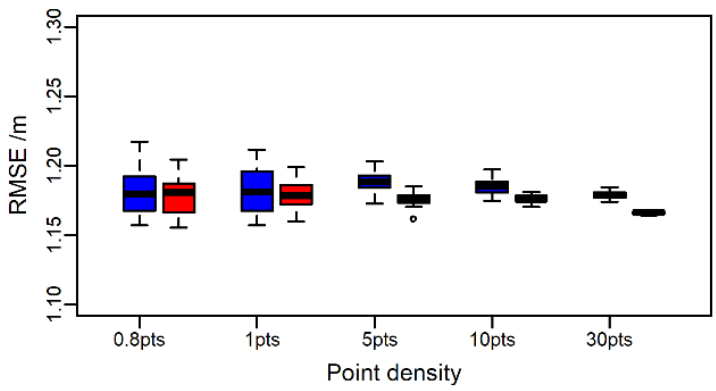

(b4)

Figure 12. Boxplots of forest stand height estimates using thinned point clouds. (a1,b1) for mean height, (a2,b2) for Lorey's height, $(\mathbf{a} 3, \mathbf{b} 3)$ for dominated height, $(\mathbf{a} 4, \mathbf{b} 4)$ for median height.

\section{Discussion}

In this study, a low-cost and consumer-grade UAV was used to acquire photogrammetry images. Meanwhile, LiDAR point clouds were acquired using a Riegl VUX-1 laser scanner mounted on a RC6-2 UAV aircraft with eight-rotors to better assess the threedimensional mapping of photogrammetry images, mainly including the capacity of ULS and USP data for forest stand height estimation, and the effect of point cloud density on the estimation accuracy of the four stand heights. The results demonstrated that the USP performed basically as well as ULS for the continuous coniferous plantation, except for the ability of generating terrain information, which were basically in line with the outcomes from previous studies [28]. 


\subsection{The Capability of USP and ULS to Estimate Forest Stand Heights}

For the four forest stand heights, our results showed that USP performed basically as well as ULS in estimating the forest stand heights, indicating that USP with LiDAR DEM could also achieve the same level of accuracy for stand height estimation at the plot level as well as ULS. Meanwhile, the estimated results from CHM were also similar with those of the point clouds.

Among the four forest stand heights, Lorey's height was the most accurately estimated, followed by dominated height, mean height, and median height, indicating that Lorey's height was the best parameter representing the forest stand height, which can also be found in $[4,42]$. The four stand heights were calculated using different methods. Lorey's height is the weighted height of DBH and tree height, and has better representativeness and stability for a stand with different ages. The dominate height was calculated using the $20 \%$ tallest trees, which mostly came from the upper trees rather than depressed trees and could be easily detected from CHM or point clouds as a result of having a strong correlation with the upper height percentiles. Furthermore, with the increasing height, the characterization of the canopy became more and more accurate, especially for $\mathrm{CHM}$ and point clouds from photogrammetry. However, mean height and median height took the average and median of all heights within each plot, respectively, which were directly related to the height distribution of each plot including the pressed tree in the understory, and also easily affected by the measurement error, causing a lower estimation accuracy than Lorey's height and dominated height.

Additionally, compared with the results using other parametric [43] or non-parametric methods [27] conducted in other studies, the simple linear regression utilized in this study was confirmed with high accuracy and having a better performance, which may be attributed to the characteristics of coniferous plantations.

\subsection{The Best Explanatory Variables for Forest Stand Heights}

The selected best explanatory variables had direct theoretical significance with the four stand heights and were mostly consistent with other studies. The difference between the best variables for ULS and USP were mainly caused by the vertical height distribution characteristics of its height metrics (Tables A1 and A2). The phenomenon that the best explanatory variable from P-NPC and P-CHM were basically consistent was attributed to the lower variation in height for the USP data, causing the same height percentile to take a similar height value. On the other hand, the variety of the best explanatory variables from L-NPC and L-CHM revealed that ULS was more capable of penetrating the forest canopy.

The best explanatory variables for all stand heights were all the height percentiles, which demonstrated the strong correlation between stand heights of the coniferous plantation with the height percentiles. The best explanatory variables for Lorey's height were mostly upper height percentiles such as $h_{90}$ and $h_{95}$, which was consistent with the results in $[4,18]$. Mean height was strongly correlated with median height percentiles $\left(h_{40}, h_{50}\right.$, and $h_{60}$ ), which were affected by the whole distribution of all heights of each plot. Jensen and Mathews [28] estimated the $H_{A}$ and $H_{\text {Med }}$ using $h_{\text {mean }}$ and $h_{\text {med }}$ metrics by simple linear regression with $R^{2}=0.90$ and $R^{2}=0.89$, respectively. The high height percentiles were the best variables for dominated height because the dominated height was calculated using the $20 \%$ tallest heights of each plot, representing the characteristics of upper trees. Puliti et al. [12] estimated the $H_{L}$ and $H_{\text {Dom }}$ using multiple linear regression by taking the height percentiles and density metrics as explanatory variables with $R^{2}=0.71, R M S E=1.4 \mathrm{~m}$ and $R^{2}=0.97, R M S E=0.7 \mathrm{~m}$, respectively.

\subsection{The Influence of Point Density on the Estimation Accuracy}

The varied flying height above the terrain will surely affect the spatial distribution of point density. To examine the sensitivity of forest height estimation to point density, five point densities varying from $0.8 \mathrm{pts}$ to $1 \mathrm{pts}, 5 \mathrm{pts}, 10 \mathrm{pts}$, and $30 \mathrm{pts} / \mathrm{m}^{2}$ for ULS point cloud and USP point cloud data were analyzed in this study. The predication accuracy 
of forest stand heights were slightly affected by thinned point clouds, which was mostly attributed to the height percentile metrics from different point densities showing little variability [4]. The results were also in keeping with other studies [44]. Consequently, it may be possible to take a higher flight height or lower overlap to acquire lower point cloud density, which could collect the data over the same area using a shorter time, thus potentially reducing the cost.

\subsection{The Performances of Point Clouds and CHM}

The performances were similar between the point clouds and CHM for the estimation accuracy of forest stand heights. P-CHM metrics models were mostly consistent with the results of P-NPC, rather than the correlation of the L-CHM and L-NPC metrics. As is widely known to all, USP is passive remote sensing, where the dense point clouds are extracted depending on the features existing in the images and SFM algorithms. The dense point clouds of USP were mostly gathered at the mid-to-upper canopy with lower penetration through the canopy to the ground, resulting in less height difference for the point clouds and CHM while the 3D point clouds from ULS were distributed throughout the forest canopy and ground surface [23], thus having the ability to depict more detailed characterization of the forest canopy. The distribution of point clouds resulted in differences between the corresponding height metrics.

\subsection{The Limitation of This Study}

Stereo photogrammetry has the ability to accurately estimate the large solitary crowns by individual tree detection approaches such as canopy local maxima filtering [45], watershed segmentation $[45,46]$, and region growing algorithm $[47,48]$. However, in our study site, the tree crowns are severely occluded by each other so it is difficult to accurately isolate individual trees. Additionally, the growth of the plantation in our study site is limited by crucial environmental conditions such as precipitation and energy of photosynthesis. Tall trees will usually fall down and saplings will be planted in the open areas in a rotation period. It is almost impossible to find trees with a height $>35 \mathrm{~m}$. While the study might be more representative to consider mature forest with $>35 \mathrm{~m}$ heights, we would like to explore tall trees in different study sites in future study.

The point cloud generated from USP could be normalized using the DEM based on LiDAR point cloud or other datasets. LiDAR has the ability to accurately acquire flat or complex terrain. Additionally, a good DEM can also be acquired by other methods such as ground surveying, which will be rather adequate for relatively flat terrain.

The difference between different forest types may be attributed to the distribution of heights and the morphological characteristics of Larixprincipis-rupprechtii and Pinus tabuliformis [49]. It can be seen from Figure 2 that the height distributions between LYS plots and YS plots were different, which might be caused by the ratio of different composition of stand ages for the LYS plots and YS plots, as the LYS plots had many young trees. Additionally, the growth rates and canopy shapes for the LYS and YS species were different and the canopy shape of LYS was an ellipsoid shape, while it was an inverted triangle distribution for YS within the growing age, which can also be found from the best explanatories of forest stand heights in Figure 9 for LYS and YS. The best explanatories for LYS were higher than those for YS. Racine et al. [50] also found that the species, crown closure, and age of balsam fir (Abies balsamea (L.) Mill.), paper birch (Betula papyrifera Marsh), black spruce (Picea mariana (Mill.) BSP), white spruce (Picea glauca Moench), and aspen (Populus tremuloides Michx.) within even-aged stands had an influence on their vertical distribution based on the airborne LiDAR data.

\section{Conclusions}

UAV stereo photogrammetry UAV laser scanning can be used to extract plantation height metrics in north China. For the four forest stand heights, the predication accuracy of Lorey's height was the highest, followed by dominated height, mean height, and median 
height, which meets the requirements of the plantation forest resource survey in this study. These heights can be estimated with high accuracy by simple linear regression based on the plot-level metrics. The USP cannot obtain accurate terrain information in median and high forest CC in the leaf-on season, but can be used to estimate forest heights with high accuracy combined with terrain from ULS, even with low point density. There were strong correlations between the metrics from the two UAV techniques. The forest stand heights estimated using the metrics extracted from NPC or CHM of USP were in agreement with those of ULS. The USP data including both NPC metrics and CHM metrics performed well in estimating forest stand heights, similar to the prediction accuracy of the ULS data. Additionally, the point cloud density that reduced from 30 pts to 0.8 pts had little influence on the prediction accuracy. Furthermore, point cloud and stereo images should be acquired in more circumstances such as broadleaf forest and leaf-off season to investigate the forest structure parameters in future studies.

Author Contributions: Data curation, M.L.; Formal analysis, M.L.; Funding acquisition, Q.L. and Z.L.; Methodology, M.L.; Supervision, Q.L., E.C. and Z.L.; Visualization, writing—original draft, M.L.; writing-review and editing, Q.L., E.C. and Z.L. All authors contributed to interpreting results and the improvement of the article. All authors have read and agreed to the published version of the manuscript.

Funding: This research was partially funded by the National Key R\&D Program of China (Grant number: 2020YFE0200800 \& 2017YFD0600904).

Institutional Review Board Statement: Not applicable.

Informed Consent Statement: Not applicable.

Data Availability Statement: The field data are not publicly available due to privacy of the private landowners. The availability of the USP and ULS data should adhere with the data sharing policy of the funders.

Acknowledgments: We thank Zhongchao Chen, Lei Zhao, Junpeng Zhao et al. for assisting with the field work. We thank the support of the Wangyedian forest farm, Chifeng, Inner Mongolia Autonomous Province, China for the experiments. We also thank the anonymous reviewers for their constructive comments and recommendations, which we used to significantly improve our article.

Conflicts of Interest: The authors declare no conflict of interest.

\section{Nomenclature}

$\begin{array}{ll}\text { Acronyms } & \text { Full Name } \\ \text { UAV } & \text { Unmanned Aerial Vehicle } \\ \text { ULS } & \text { UAV Laser Scanning } \\ \text { USP } & \text { UAV Stereo Photogrammetry } \\ \text { DEM } & \text { Digital Elevation Model } \\ \text { DSM } & \text { Digital Surface Model } \\ \text { NPC } & \text { Normalized Point Clouds } \\ \text { L-NPC } & \text { NPC of LiDAR } \\ \text { P-NPC } & \text { NPC of USP } \\ \text { CHM } & \text { Canopy Height Model } \\ \text { L-CHM } & \text { CHM of ULS } \\ \text { P-CHM } & \text { CHM of USP } \\ \text { DBH } & \text { Diameter at Breast Height } \\ H_{A} & \text { Mean height } \\ H_{L} & \text { Lorey's height } \\ H_{\text {Dom }} & \text { Dominated height } \\ H_{\text {Med }} & \text { Median height } \\ & \end{array}$




\section{Appendix A}

Table A1. Comparison of metrics from normalized point clouds and CHM.

\begin{tabular}{|c|c|c|c|c|c|c|c|c|c|c|c|c|}
\hline & \multicolumn{2}{|c|}{$\begin{array}{c}\text { All Plots } \\
\text { NPC Metrics }\end{array}$} & \multicolumn{2}{|c|}{$\begin{array}{l}\text { LYS Plots } \\
\text { NPC Metrics }\end{array}$} & \multicolumn{2}{|c|}{$\begin{array}{c}\text { YS Plots } \\
\text { NPC Metrics }\end{array}$} & \multicolumn{2}{|c|}{$\begin{array}{c}\text { All Plots } \\
\text { CHM Metrics }\end{array}$} & \multicolumn{2}{|c|}{$\begin{array}{l}\text { LYS Plots } \\
\text { CHM Metrics }\end{array}$} & \multicolumn{2}{|c|}{$\begin{array}{c}\text { YS Plots } \\
\text { CHM Metrics }\end{array}$} \\
\hline & $M D$ & $r$ & $M D$ & $r$ & $M D$ & $r$ & $M D$ & $r$ & $M D$ & $r$ & $M D$ & $r$ \\
\hline$h_{10}$ & -2.180 & 0.962 & -1.947 & 0.965 & -2.351 & 0.962 & -2.076 & 0.948 & -1.807 & 0.955 & -2.273 & 0.939 \\
\hline$h_{20}$ & -1.591 & 0.976 & -1.388 & 0.981 & -1.740 & 0.970 & -1.405 & 0.972 & -1.181 & 0.979 & -1.569 & 0.963 \\
\hline$h_{30}$ & -1.270 & 0.984 & -1.121 & 0.986 & -1.379 & 0.980 & -1.050 & 0.982 & -0.887 & 0.988 & -1.170 & 0.975 \\
\hline$h_{40}$ & -1.022 & 0.989 & -0.922 & 0.990 & -1.096 & 0.986 & -0.795 & 0.988 & -0.694 & 0.991 & -0.869 & 0.984 \\
\hline$h_{50}$ & -0.828 & 0.991 & -0.757 & 0.993 & -0.880 & 0.988 & -0.596 & 0.990 & -0.529 & 0.994 & -0.645 & 0.987 \\
\hline$h_{60}$ & -0.660 & 0.992 & -0.616 & 0.994 & -0.692 & 0.989 & -0.425 & 0.993 & -0.394 & 0.995 & -0.448 & 0.990 \\
\hline$h_{70}$ & -0.500 & 0.993 & -0.492 & 0.995 & -0.506 & 0.991 & -0.278 & 0.994 & -0.277 & 0.996 & -0.278 & 0.992 \\
\hline$h_{80}$ & -0.322 & 0.995 & -0.354 & 0.996 & -0.298 & 0.993 & -0.116 & 0.995 & -0.159 & 0.997 & -0.084 & 0.994 \\
\hline$h_{90}$ & -0.130 & 0.995 & -0.184 & 0.996 & -0.090 & 0.993 & 0.051 & 0.995 & -0.007 & 0.997 & 0.093 & 0.994 \\
\hline$h_{95}$ & -0.009 & 0.995 & -0.074 & 0.996 & 0.039 & 0.993 & 0.150 & 0.996 & 0.090 & 0.997 & 0.194 & 0.994 \\
\hline$h_{\max }$ & -0.012 & 0.977 & -0.014 & 0.970 & -0.011 & 0.986 & -0.004 & 0.977 & -0.008 & 0.971 & -0.002 & 0.985 \\
\hline$h_{\text {mean }}$ & -1.030 & 0.990 & -0.959 & 0.991 & -1.081 & 0.989 & -0.842 & 0.988 & -0.766 & 0.990 & -0.898 & 0.987 \\
\hline$h_{\text {med }}$ & -0.828 & 0.991 & -0.757 & 0.993 & -0.880 & 0.988 & -0.596 & 0.990 & -0.529 & 0.994 & -0.645 & 0.987 \\
\hline$h_{\mathrm{cV}}$ & 0.096 & 0.848 & 0.087 & 0.832 & 0.103 & 0.863 & 0.093 & 0.797 & 0.081 & 0.793 & 0.102 & 0.797 \\
\hline$h_{\mathrm{sd}}$ & 0.869 & 0.834 & 0.818 & 0.640 & 0.907 & 0.885 & 0.901 & 0.807 & 0.831 & 0.632 & 0.951 & 0.864 \\
\hline$h_{I Q}$ & 1.002 & 0.859 & 0.816 & 0.629 & 1.139 & 0.889 & 1.013 & 0.861 & 0.794 & 0.709 & 1.174 & 0.887 \\
\hline
\end{tabular}

Table A2. The explanatory variables and parameters of different forest stand heights from the ULS and USP metrics.

\begin{tabular}{|c|c|c|c|c|c|c|c|c|c|c|c|c|}
\hline \multirow{2}{*}{ Height } & \multicolumn{3}{|c|}{ L-NPC Metrics } & \multicolumn{3}{|c|}{ L-CHM Metrics } & \multicolumn{3}{|c|}{ P-NPC Metrics } & \multicolumn{3}{|c|}{ P-CHM Metrics } \\
\hline & ALL & LYS & YS & ALL & LYS & YS & ALL & LYS & YS & ALL & LYS & YS \\
\hline \multirow{3}{*}{$H_{A}$} & $h_{50}$ & $h_{60}$ & & $h_{40}$ & $h_{50}$ & $h_{30}$ & $h_{40}$ & $h_{50}$ & $h_{30}$ & $h_{40}$ & $h_{50}$ & $h_{40}$ \\
\hline & $\mathrm{a}=0.859$ & $a=1.667$ & $a=$ & $\mathrm{a}=0.971$ & $\mathrm{a}=1.418$ & $\mathrm{a}=0.256$ & $\mathrm{a}=0.108$ & $\mathrm{a}=1.003$ & $\mathrm{a}=$ & $\mathrm{a}=0.005$ & $\mathrm{a}=0.949$ & $a=$ \\
\hline & $\mathrm{b}=1.037$ & $\mathrm{~b}=0.936$ & $\mathrm{~b}=1.237$ & $\mathrm{~b}=1.054$ & $\mathrm{~b}=0.971$ & $\mathrm{~b}=1.210$ & $\mathrm{~b}=1.061$ & $b=0.967$ & $\mathrm{~b}=1.237$ & $b=1.065$ & $\mathrm{~b}=0.968$ & $\mathrm{~b}=1.211$ \\
\hline \multirow{3}{*}{$H_{L}$} & $h_{80}$ & $h_{90}$ & $h_{80}$ & $h_{80}$ & $h_{90}$ & $h_{70}$ & $h_{70}$ & $h_{80}$ & $h_{60}$ & $h_{70}$ & $h_{80}$ & $h_{60}$ \\
\hline & $a=0.339$ & $\mathrm{a}=0.506$ & $a=$ & $\mathrm{a}=0.073$ & $\mathrm{a}=$ & $\mathrm{a}=$ & $a=0.053$ & $\mathrm{a}=0.489$ & $a=$ & $\mathrm{a}=$ & $\mathrm{a}=0.449$ & $a=$ \\
\hline & $\mathrm{b}=1.019$ & $\mathrm{~b}=0.961$ & $\mathrm{~b}=1.093$ & $\mathrm{~b}=1.018$ & $b=0.981$ & $\mathrm{~b}=1.079$ & $\mathrm{~b}=1.050$ & $b=0.987$ & $b=1.160$ & $\mathrm{~b}=1.051$ & $\mathrm{~b}=0.985$ & $\mathrm{~b}=1.168$ \\
\hline \multirow{3}{*}{$H_{\text {Dom }}$} & $h_{90}$ & $h_{95}$ & $h_{90}$ & $h_{90}$ & $h_{90}$ & $h_{80}$ & $h_{80}$ & $h_{90}$ & $h_{80}$ & $h_{80}$ & $h_{80}$ & $h_{80}$ \\
\hline & $\mathrm{a}=0.898$ & $\mathrm{a}=1.057$ & $\mathrm{a}=0.051$ & $a=0.611$ & $\mathrm{a}=0.975$ & $\mathrm{a}=0.764$ & $\mathrm{a}=0.975$ & $\mathrm{a}=1.070$ & $\mathrm{a}=0.071$ & $a=0.889$ & $\mathrm{a}=1.490$ & $a=$ \\
\hline & $\mathrm{b}=1.056$ & $\mathrm{~b}=1.005$ & $\mathrm{~b}=1.121$ & $\mathrm{~b}=1.057$ & $\mathrm{~b}=1.030$ & $\mathrm{~b}=1.113$ & $\mathrm{~b}=1.087$ & $\mathrm{~b}=1.029$ & $\mathrm{~b}=1.165$ & $\mathrm{~b}=1.087$ & $\mathrm{~b}=1.033$ & $\mathrm{~b}=1.171$ \\
\hline \multirow{3}{*}{$H_{M e d}$} & $h_{50}$ & $h_{70}$ & $h_{30}$ & $h_{40}$ & $h_{60}$ & $h_{30}$ & $h_{30}$ & $h_{50}$ & $h_{10}$ & $h_{30}$ & $h_{50}$ & $h_{10}$ \\
\hline & $a=0.618$ & $\mathrm{a}=0.980$ & $a=$ & $\mathrm{a}=0.740$ & $\mathrm{a}=0.751$ & $\mathrm{a}=$ & $\mathrm{a}=0.139$ & $\mathrm{a}=0.673$ & $\mathrm{a}=$ & $a=0.025$ & $\mathrm{a}=0.619$ & $\mathrm{a}=$ \\
\hline & $\mathrm{b}=1.082$ & $\mathrm{~b}=0.980$ & $\mathrm{~b}=1.358$ & $\mathrm{~b}=1.100$ & $\mathrm{~b}=1.013$ & $\mathrm{~b}=1.269$ & $\mathrm{~b}=1.120$ & $\mathrm{~b}=1.017$ & $\mathrm{~b}=1.388$ & $\mathrm{~b}=1.126$ & $\mathrm{~b}=1.018$ & $\mathrm{~b}=1.376$ \\
\hline
\end{tabular}

\section{References}

1. Food and Agriculture Organization of the United Nations (FAO). Global Forest Resources Assessment 2015: How Are the World's Forests Changing? FAO: Rome, Italy, 2015; pp. 1-48. Available online: https://www.uncclearn.org/wp-content/uploads/library/ a-i4793e.pdf (accessed on 20 May 2021).

2. Jim, C.; Peter, H. Wood From Planted Forests: A Global Outlook 2005-2030. Acta Phytoecol. Sin. 2008, $28,210-217$.

3. Pawson, S.M.; Brin, A.; Brockerhoff, E.G.; Lamb, D.; Payn, T.W.; Paquette, A.; Parrotta, J.A. Plantation forests, climate change and biodiversity. Biodivers. Conserv. 2013, 22, 1203-1227. [CrossRef]

4. Liu, K.; Shen, X.; Cao, L.; Wang, G.; Cao, F. Estimating forest structural attributes using UAV-LiDAR data in Ginkgo plantations. ISPRS J. Photogramm. Remote Sens. 2018, 146, 465-482. [CrossRef]

5. Dash, J.P.; Marshall, H.M.; Brian, R. Methods for estimating multivariate stand yields and errors using k-NN and aerial laser scanning. For. Int. J. For. Res. 2015, 88, 237-247. [CrossRef]

6. Selkowitz, D.J.; Green, G.; Peterson, B.; Wylie, B. A multi-sensor lidar, multi-spectral and multi-angular approach for mapping canopy height in boreal forest regions. Remote Sens. Environ. 2012, 121, 458-471. [CrossRef]

7. Zarco-Tejada, P.J.; Diaz-Varela, R.; Angileri, V.; Loudjani, P. Tree height quantification using very high resolution imagery acquired from an unmanned aerial vehicle (UAV) and automatic 3D photo-reconstruction methods. Eur. J. Agron. 2014, 55, 89-99. [CrossRef] 
8. Okojie, J. Assessment of Forest Tree Structural Parameter Extractability from Optical Imaging UAV Datasets, in Ahaus Germany. Master's Thesis, University of Twente, Enschede, The Netherlands, 2017.

9. Kankare, V.; Holopainen, M.; Vastaranta, M.; Puttonen, E.; Yu, X.; Hyyppae, J.; Vaaja, M.; Hyyppae, H.; Alho, P. Individual tree biomass estimation using terrestrial laser scanning. ISPRS J. Photogramm. Remote Sens. 2013, 75, 64-75. [CrossRef]

10. Okojie, J.A.; Okojie, L.O.; Effiom, A.E.; Odia, B.E. Relative canopy height modelling precision from UAV and ALS datasets for forest tree height estimation. Remote. Sens. Appl. Soc. Environ. 2020, 17, 100284. [CrossRef]

11. Lim, K.; Treitz, P.; Wulder, M.; St-Onge, B.T.; Flood, M. LiDAR remote sensing of forest structure. Prog. Phys. Geog. 2003, 27, 88-106. [CrossRef]

12. Puliti, S.; Ørka, H.; Gobakken, T.; Næsset, E. Inventory of Small Forest Areas Using an Unmanned Aerial System. Remote Sens. 2015, 7, 9632-9654. [CrossRef]

13. Puliti, S.; Saarela, S.; Gobakken, T.; Ståhl, G.; Næsset, E. Combining UAV and Sentinel-2 auxiliary data for forest growing stock volume estimation through hierarchical model-based inference. Remote Sens. Environ. 2018, 204, 485-497. [CrossRef]

14. Maltamo, M.; Næsset, E.; Vauhkonen, J. Forestry Applications of Airborne Laser Scanning: Concepts and Case Studies. Manag. Ecosys. 2014, 27, 2014.

15. Jonas, B.; Jrgen, W.; Franssonsupa, J.E.S. Forest variable estimation using photogrammetric matching of digital aerial images in combination with a high-resolution DEM. Scand. J. Forest Res. 2012, 27, 692-699.

16. Iqbal, I.A.; Musk, R.A.; Osborn, J.; Stone, C.; Lucieer, A. A comparison of area-based forest attributes derived from airborne laser scanner, small-format and medium-format digital aerial photography. Int. J. Appl. Earth Obs. 2019, 76, 231-241. [CrossRef]

17. Antonio Navarro, J.; Fernandez-Landa, A.; Luis Tome, J.; Luz Guillen-Climent, M.; Carlos Ojeda, J. Testing the quality of forest variable estimation using dense image matching: A comparison with airborne laser scanning in a Mediterranean pine forest. Int. J. Remote Sens. 2018, 39, 1-17.

18. White, J.; Stepper, C.; Tompalski, P.; Coops, N.; Wulder, M. Comparing ALS and Image-Based Point Cloud Metrics and Modelled Forest Inventory Attributes in a Complex Coastal Forest Environment. Forests 2015, 6, 3704-3732. [CrossRef]

19. Cao, L.; Liu, H.; Fu, X.; Zhang, Z.; Ruan, H. Comparison of UAV LiDAR and Digital Aerial Photogrammetry Point Clouds for Estimating Forest Structural Attributes in Subtropical Planted Forests. Forests 2019, 10, 145. [CrossRef]

20. Noordermeer, L.; Bollandsås, O.M.; Ørka, H.O.; Næsset, E.; Gobakken, T. Comparing the accuracies of forest attributes predicted from airborne laser scanning and digital aerial photogrammetry in operational forest inventories. Remote Sens. Environ. 2019, 226, 26-37. [CrossRef]

21. Ullah, S.; Adler, P.; Dees, M.; Datta, P.; Weinacker, H.; Koch, B. Comparing image-based point clouds and airborne laser scanning data for estimating forest heights. Iforest Biogeosci. For. 2017, 10, 273-280. [CrossRef]

22. Mielcarek, M.; Kamińska, A.; Stereńczak, K. Digital Aerial Photogrammetry (DAP) and Airborne Laser Scanning (ALS) as Sources of Information about Tree Height: Comparisons of the Accuracy of Remote Sensing Methods for Tree Height Estimation. Remote Sens. 2020, 12, 1808. [CrossRef]

23. Vastaranta, M.; Wulder, M.A.; White, J.C.; Pekkarinen, A.; Tuominen, S.; Ginzler, C.; Kankare, V.; Holopainen, M.; Hyyppä, J.; Hyyppä, H. Airborne laser scanning and digital stereo imagery measures of forest structure: Comparative results and implications to forest mapping and inventory update. Can. J. Remote Sens. 2013, 39, 382-395. [CrossRef]

24. Lennart, N.; Martin, B.S.O.; Terje, G.; Erik, N.S. Direct and indirect site index determination for Norway spruce and Scots pine using bitemporal airborne laser scanner data. For. Ecol. Manag. 2018, 428, 104-114. [CrossRef]

25. Zhao, K.; Suarez, J.C.; Garcia, M.; Hu, T.; Wang, C.; Londo, A. Utility of multitemporal lidar for forest and carbon monitoring: Tree growth, biomass dynamics, and carbon flux. Remote Sens. Environ. 2017, 204, 883-897. [CrossRef]

26. Gleason, C.J.; Im, J. Forest biomass estimation from airborne LiDAR data using machine learning approoaches. Remote Sens. Environ. 2012, 125, 80-91. [CrossRef]

27. Järnstedt, J.; Pekkarinen, A.; Tuominen, S.; Ginzler, C.; Holopainen, M.; Viitala, R. Forest variable estimation using a highresolution digital surface model. ISPRS J. Photogramm. Remote Sens. 2012, 74, 78-84. [CrossRef]

28. Jensen, J.L.R.; Mathews, A.J. Assessment of Image-Based Point Cloud Products to Generate a Bare Earth Surface and Estimate Canopy Heights in a Woodland Ecosystem. Remote Sens. 2016, 8, 50. [CrossRef]

29. Tompalski, P.; White, J.C.; Coops, N.C.; Wulder, M.A. Quantifying the contribution of spectral metrics derived from digital aerial photogrammetry to area-based models of forest inventory attributes. Remote. Sens. Environ. 2019, 234, 111434. [CrossRef]

30. Ruiz, L.; Hermosilla, T.; Mauro, F.; Godino, M. Analysis of the Influence of Plot Size and LiDAR Density on Forest Structure Attribute Estimates. Forests 2014, 5, 936-951. [CrossRef]

31. Lovell, J.L.; Jupp, D.L.B.; Newnham, G.J.; Coops, N.C.; Culvenor, D.S. Simulation study for finding optimal lidar acquisition parameters for forest height retrieval. For. Ecol. Manag. 2005, 214, 398-412. [CrossRef]

32. Mattias, M.; Fransson, J.E.S.; Johan, H. Effects on estimation accuracy of forest variables using different pulse density of laser data. For. Sci. 2007, 53, 619-626.

33. Garcia, M.; Saatchi, S.; Ferraz, A.; Silva, C.A.; Ustin, S.; Koltunov, A.; Balzter, H. Impact of data model and point density on aboveground forest biomass estimation from airborne LiDAR. Carbon Balance Manag. 2017, 12, 1-18. [CrossRef]

34. Popescu, S.C.; Wynne, R.H.; Nelson, R.F. Estimating plot-level tree heights with lidar: Local filtering with a canopy-height based variable window size. Comput. Electron. Agr. 2002, 37, 71-95. [CrossRef] 
35. Verhoeven, G. Taking computer vision aloft-archaeological three-dimensional reconstructions from aerial photographs with photoscan. Archaeol. Prospect. 2011, 18, 67-73. [CrossRef]

36. Liu, Q.W.; Fu, L.; Chen, Q.; Wang, G.X.; Luo, P.; Sharma, R.P.; He, P.; Li, M.; Wang, M.X.; Duan, G.S. Analysis of the Spatial Differences in Canopy Height Models from UAV LiDAR and Photogrammetry. Remote Sens. 2020, 12, 2884. [CrossRef]

37. $\mathrm{Wu}, \mathrm{B}$.; Tang, S.J. Review of geometric fusion of remote sensing imagery and laser scanning data. Int. J. Image Data Fusion 2015, 6, 1-18. [CrossRef]

38. Ni, W.J.; Sun, G.Q.; Pang, Y.; Zhang, Z.Y.; Liu, J.L.; Yang, A.Q.; Wang, Y.; Zhang, D.F. Mapping Three-Dimensional Structures of Forest Canopy Using UAV Stereo Imagery: Evaluating Impacts of Forward Overlaps and Image Resolutions with LiDAR Data as Reference. IEEE J. Sel. Top. Appl. Earth Obs. Remote. Sens. 2018, 11, 3578-3589. [CrossRef]

39. Pyrl, J.; Saarinen, N.; Kankare, V.; Coops, N.C.; Vastaranta, M. Variability of wood properties using airborne and terrestrial laser scanning. Remote Sens. Environ. 2019, 235, 111474.

40. Mcgaughey, R.J. FUSION/LDV: Software for LIDAR Data Analysis and Visualization; Pacific Northwest Research Station; University of Washington: Seattle, WA, USA, 2013.

41. Næsset, E. Predicting forest stand characteristics with airborne scanning laser using a practical two-stage procedure and field data. Remote Sens. Environ. 2002, 80, 88-99. [CrossRef]

42. Bottalico, F.; Chirici, G.; Giannini, R.; Mele, S.; Mura, M.; Puxeddu, M.; Mcroberts, R.E.; Valbuena, R.; Travaglini, D. Modeling Mediterranean forest structure using airborne laser scanning data. Int. J. Appl. Earth Obs. 2017, 57, 145-153. [CrossRef]

43. Gobakken, T.; Bollandsås, O.M.; Næsset, E. Comparing biophysical forest characteristics estimated from photogrammetric matching of aerial images and airborne laser scanning data. Scand. J. For. Res. 2015, 30, 73-86. [CrossRef]

44. Silva, C.A.; Hudak, A.; Vierling, L.A.; Klauberg, C.; Garcia, M.; Ferraz, A.; Keller, M.; Eitel, J.; Saatchi, S. Impacts of Airborne Lidar Pulse Density on Estimating Biomass Stocks and Changes in a Selectively Logged Tropical Forest. Remote Sens. 2017, 9, 1068. [CrossRef]

45. Tesfamichael, S.G.; Aardt, J.A.N.V.; Ahmed, F. Estimating plot-level tree height and volume of Eucalyptus grandis plantations using small-footprint, discrete return lidar data. Prog. Phys. Geog. 2010, 34, 515-540. [CrossRef]

46. Goldbergs, G.; Maier, S.; Levick, S.; Edwards, A. Efficiency of Individual Tree Detection Approaches Based on Light-Weight and Low-Cost UAS Imagery in Australian Savannas. Remote Sens. 2018, 10, 161. [CrossRef]

47. Li, W.K.; Guo, Q.H.; Jakubowski, M.K.; Kelly, M. A New Method for Segmenting Individual Trees from the Lidar Point Cloud. Photogramm. Eng. Remote Sens. 2012, 78, 75-84. [CrossRef]

48. Hirschmugl, M.; Ofner, M.; Raggam, J.; Schardt, M.S. Single tree detection in very high resolution remote sensing data. Remote Sens. Environ. 2007, 110, 533-544. [CrossRef]

49. Li, Y.C.; Li, C.; Li, M.; Liu, Z. Influence of Variable Selection and Forest Type on Forest Aboveground Biomass Estimation Using Machine Learning Algorithms. Forests 2019, 10, 1073. [CrossRef]

50. Racine, E.; Coops, N.C.; Bégin, J.; Myllymki, M. Species, crown closure, and age as determinants of the vertical distribution of airborne LiDAR returns. Trees 2021. [CrossRef] 